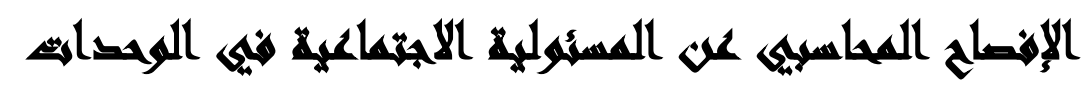

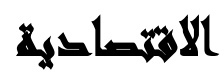

\section{[ril]}

أحمد فؤاد مندور (')- صفوت مصطفى الدويري(')- حسنية حلمي محمد سعد(')

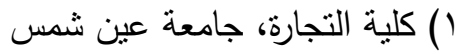

\section{المستخلئ}

يعد الإفصاح المحاسبي عن المسئولية الاجتماعية في الوحدات الاقتصادية أحد الوظائف

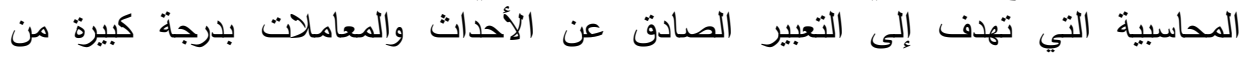

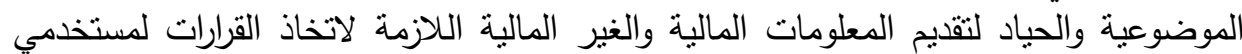

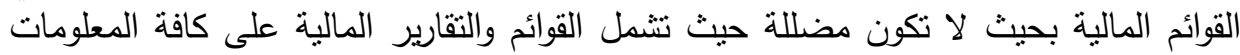

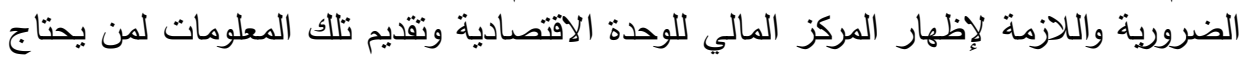
إليها بهدف اتخاذ القرارات.

ويهدف البحث إلى دراسة هدف أساسي وهو دراسة انعكاسات تأثثير الإفصاح المحاسبي

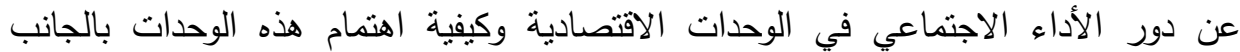
الاجتماعي والوفاء بمسئوليتها الاجتماعية تجاه المجتمع الذاعي تلعمل فئه فيه.

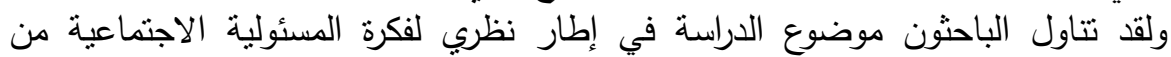

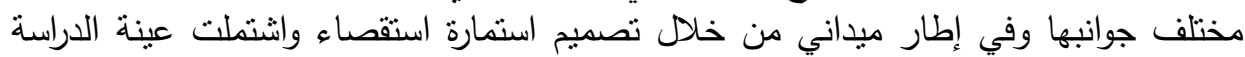

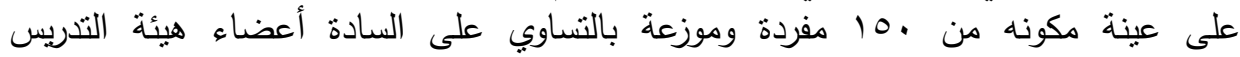
بالجامعات للاستفادة من الخبرة الأكاديمية والعلمية والسادة العاملين في شركات البات البترول (شركة التراء

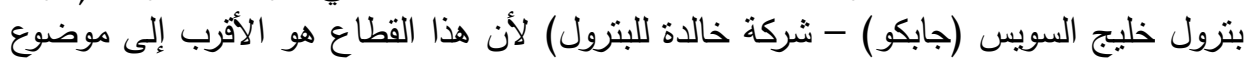
الدراسة.

وقد خلصت الدراسة الميدانية إلى عدة نتائج كان على رأسها الإقرار بأهمية المسئولية

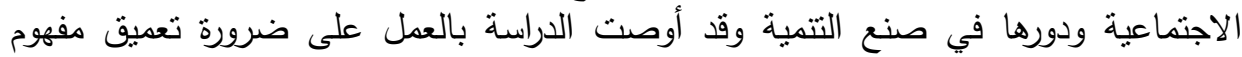

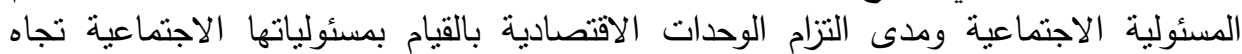

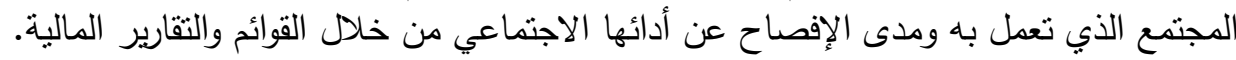




\section{المهandl}

أدى زيادة النمو في الوحدات الاقتصادية إلى التأثير على المجتمع والبيئة، مما أدى إلى الى التى زيادة منطلبات المجتمع من الوحدات الاقتصادية ليس بإضافة قيمة اقتصادية فحسب بل بل أيضاً

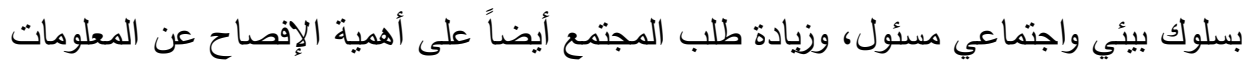

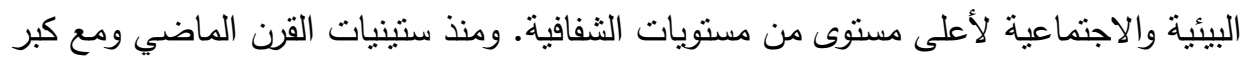

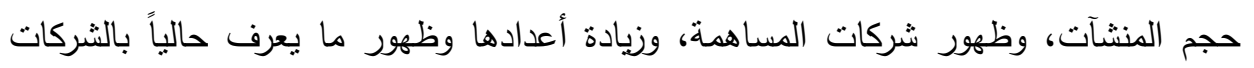

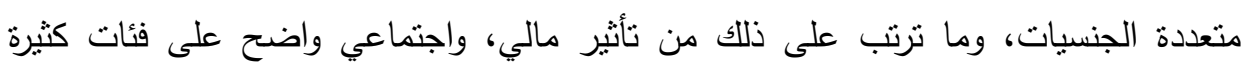

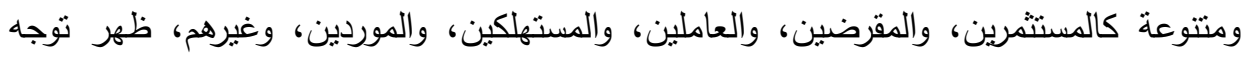

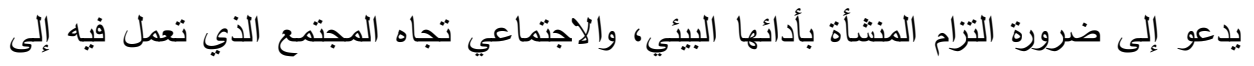

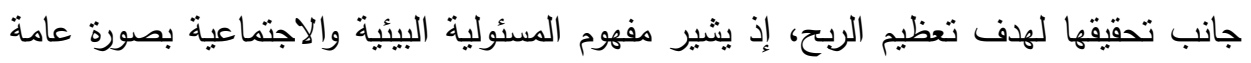

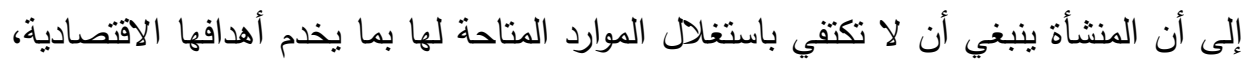

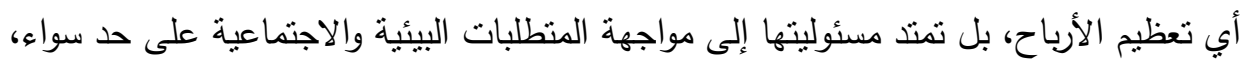

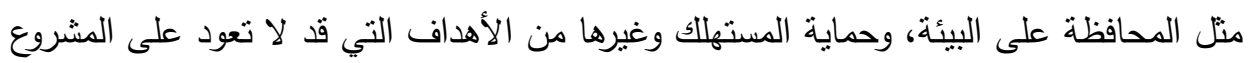

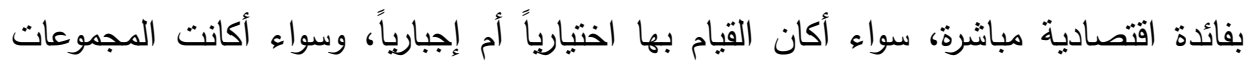

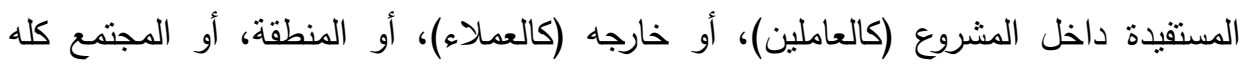

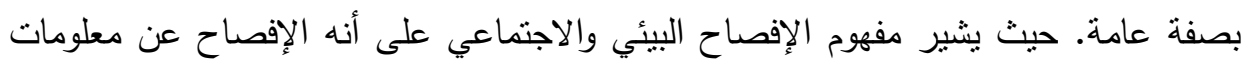

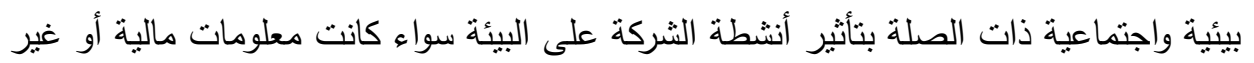

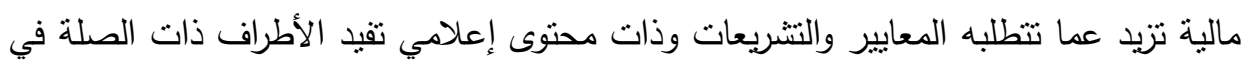
تقييم ماضي وحاضر ومستقبل الشركة عما قامت به من ممارسات تجاه البيئة والمجتمع، وتأثير ونير

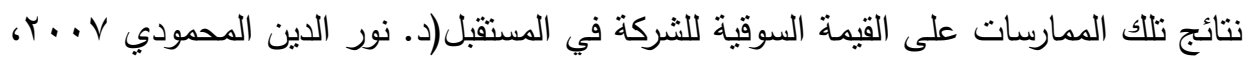

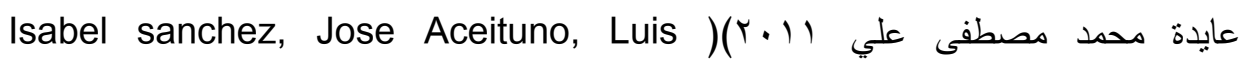

(Rodriguez, 2013 
ولذلك ظهر مفهوم وإطار فكري محاسبي جديد يسمى بالمحاسبة الاجتماعية للمحاولة في

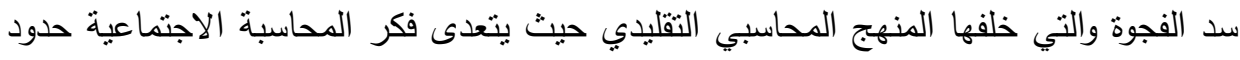
الإطار التقليدي من التركيز على الأرباح فحسب بل التعامل مع العوامل الخارجية الأخرى والتي لني تعتبر من أكبر الأثز على عملية التتمبة المستدامة وتتمنل في الموارد الطبيعية ومنها الماء -

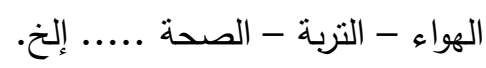

وبناء على ذلك تحول التركيز من مجرد الإفصاح عن المعلومات المالية إلى ضرورة الإفصاح عن المعلومات الاجتماعبة من خلال التقارير والقوائم المالية للوحدات الاقتصادية وملحقاتها والتي تساهم في اتخاذ قرارات مالية واقتصادية رشيدة وتشجيع الاستثمارات في ظل لإنل بيئة تتسم بضخامة القوانين والتشريعات البيئية والاجتماعية الملزمة للمستخدمين.

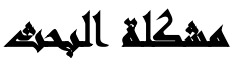

تتمنل مشكلة البحث في أن الإفصاح المحاسبي عن المسئولية الاجتماعية في الوحدات

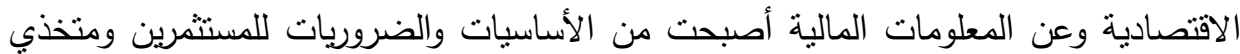

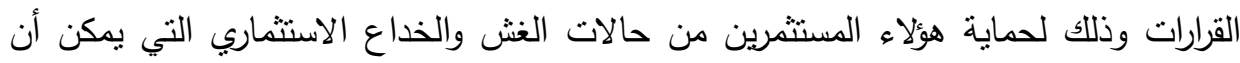
يتعرضوا لها في حالة التضليل عن الإفصاح المحاسبي عن المعلومات المالية. وقد سبق وأن أنثارت الدراسات السابقة لمشكلة البحث حيث تعرضت دراسة (عبد الله

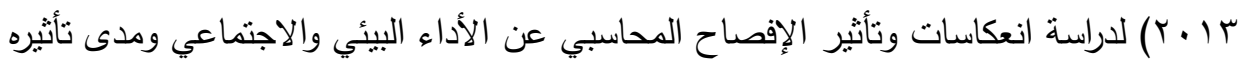
على القدرة التتافسية للوحدات الاقتصادية وإمكانية مساهمة الإفصاح المحاسبي عن الإداهي المسئولية

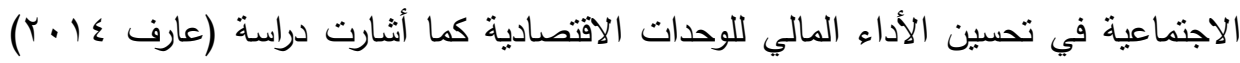
بتوضيح مفهوم المسئولية الاجتماعية ومجالاتها وأسباب تزايد الاهنمام بها ومبادئها وكيفية

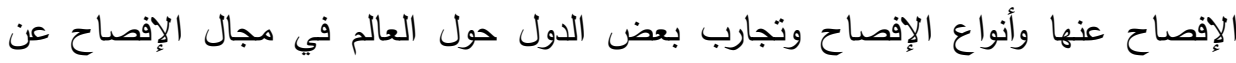
المسئولية الاجتماعية وجهود المنظمات المهنية في دعم الإفصاح المحاسبي عن المسئولية

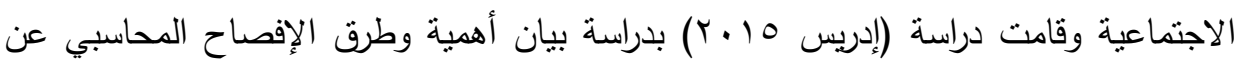

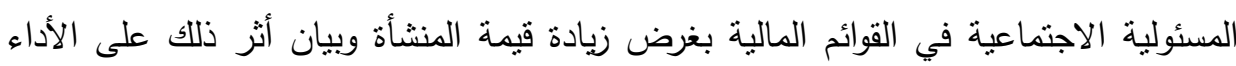

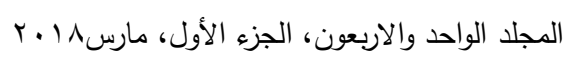


المالي للوحدات الاقتصادية ومدى الإلزام بهذه الإقصاحات في التقارير والقوائم المالية (محمد

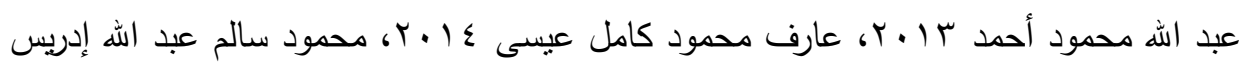

من خلال ما سبق يمكن القول بأن المشكلة الأساسية التي يواجهها البحث يمكن أن تتضح

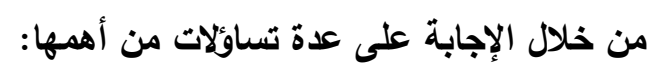
- هل يعتبر نشاط الوحدات الاقتصادية في مجال مكافحة تلوث البيئة أحد الأنشطة المطلوبة الإبه

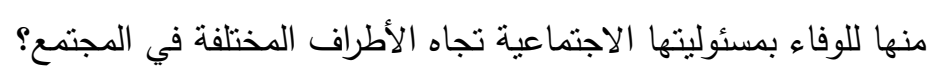

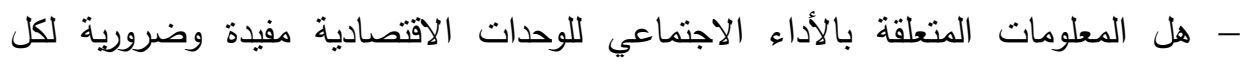

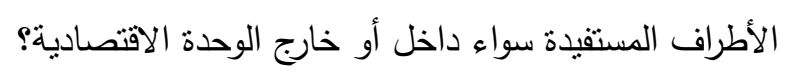
- هل يساعد الإفصاح المحاسبي عن الأداء الاجتماعي للوحدة الاقتصادية عن مدى التزام الأفرادئ

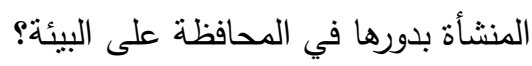
- هل الرقابة على أداء الوحدات الاقتصادية بصفة مستمرة سوف يسمح لهذه الوحدات من لندات

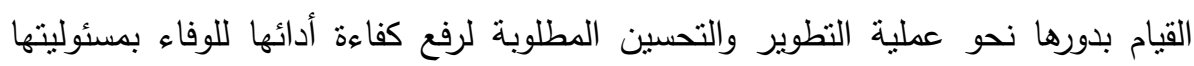

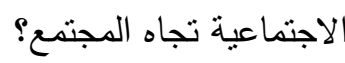

\section{أهفاهن المهيه:}

- يهدف البحث إلى هدف أساسي ورئيسي وهو دراسة انعكاسات تأثير الإقصاح المحاسبي عن الأداء

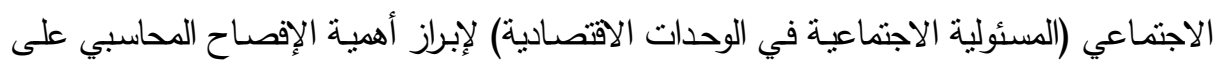
زبيادة السمعة الطيبة للوحدات الاقتصادية وذلك من خلد الأهداف الفرعية التالية:

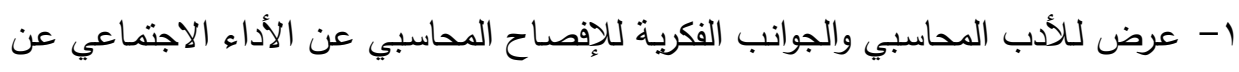
المسئولية الاجتماعية. r- تحليــ أوجـهـ القصـور فـي المحاسبة عـن الأداء الاجتمـاعي للمسئولية الاجتماعيـة في الوحـدات الاقتصانية. 
r- عرض انعكاس المحاسبة عن الأداء الاجتماعي على تحقيق وزيادة السمعة الطيبة للوحدات الاقتصادية وتحقيق مفهوم التتمية المستدامة.

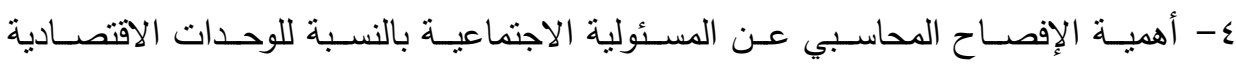
ومستخدمي القوائم والتقارير المالية ومتخذي القرارات والمستثمرين.

\section{ألهan}

يستمد هذا البحث أهميته من أهمية الموضوع الذي يتصدى له وعلى ضوء مشكلة البحث والهدف منه وهو النأكيد على أهمية الإفصاح المحاسبي عن المسئولية الاجتماعية في الوحدات

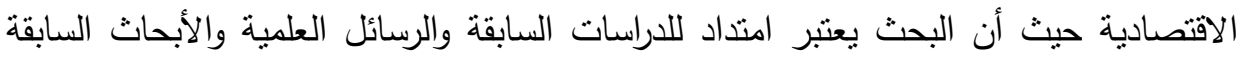

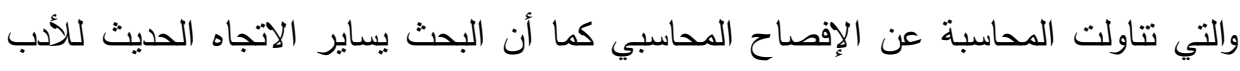

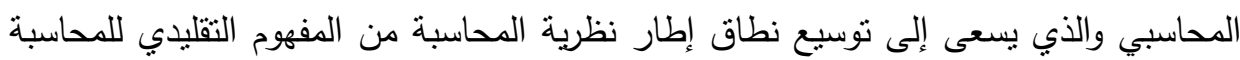

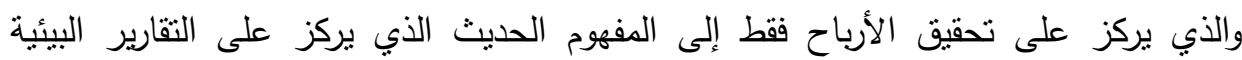
والاجتماعية بجانب التقارير المالية.

\section{هزوض المهمه}

في ضوء طبيعة مشكلة البحث وما هو مستهدف من دراسته يمكن وضع الفروض التالية: 1-لا توجد علاقة معنوية بين التزام المنشأة بالمسئولية الاجتماعية ومنع التلوث في المياه والتزبة.

r- لا توجد علاقة معنوية بين التزام المنشأة بالمسئولية الاجتماعية ومساهمة المنشأة في توفير

$$
\text { فرص العمل. }
$$

r-لا توجد علاقة معنوية بين التزام المنشأة بالمسئولية الاجتماعية وتوفير الرفاهية المادية

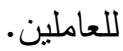




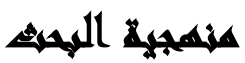

في إطار محاولة تحقيق أهداف البحث وفروضه تتبع الباحثة الجانب النظري على النحو التالي:

1-المنهج الاستقرائي:حيث يتم استقراء الفكر المحاسبي من خلال الكنابات والدراسات

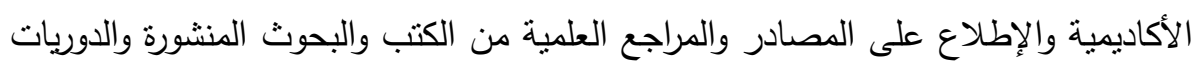

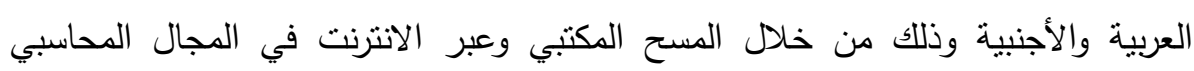

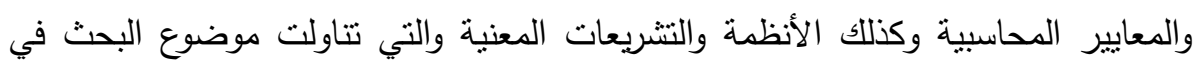
مصر

r-المنهج الاستنباطي:وهو الذي يستخدم حاضر الظواهر والأحداث ويشتمل على عمليات

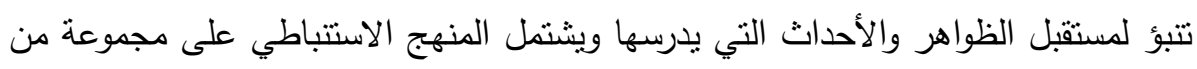

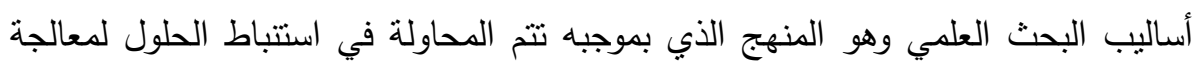
مثكلة البحث محل الدراسة. ץ-الدراسة الميدانية:نظراً لوجود عوامل لا تقبل القياس الكمي سوف تعتد الباحثة في هذه

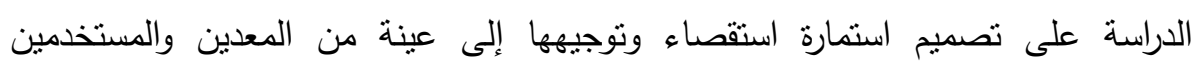

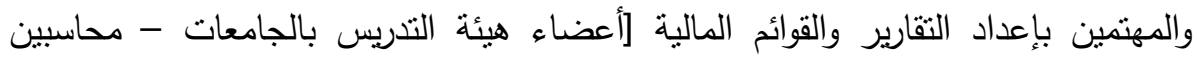

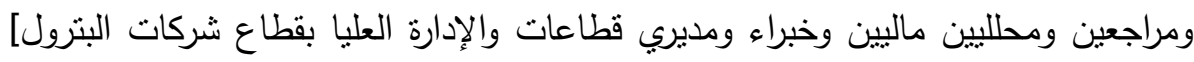
بفرض تجميع أرائهم المتعلقة بموضوع البحث مع استخدام التحليل الإحصائي للبيانات

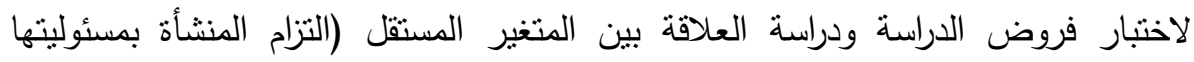
الاجتماعية) والمتغيرات النابعة (فروض الدراسية الإنة) وذللك باستخدام الأساليب الإحصائية والرياضية الملائمة لطبيعة البيانات. 


\section{التراسايت الساوية}

دراسة عبد الله(ب 1 + Y): هدف البحث إلى دراسة انعاسات وتأثير الإفصاح المحاسبي عن

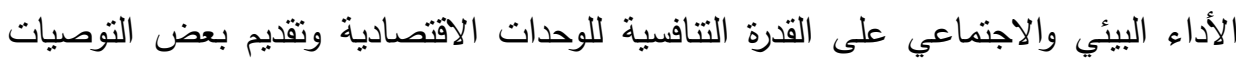

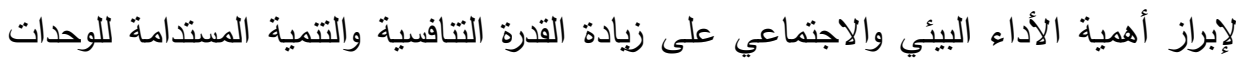

وقد توصلت الاراسة إلى عدة نتائج وهي:

1-أن تحقيق الوحدات الاقتصادية لمستوى مقبول من الإنقان الإنصاح المحاسبي عن الأداء البيئي

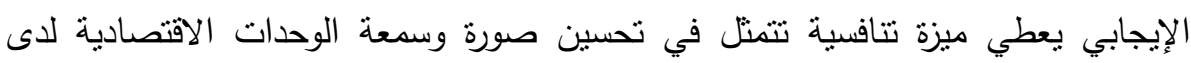

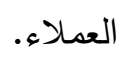

r-أن الإفصاح المحاسبي عن الأداء البيئي في القوائم والثقارير المالية هام لوقوف مستخدمي القوائم والثقارير المالية على الآثار البيئية للوحدة الاقتصادية.

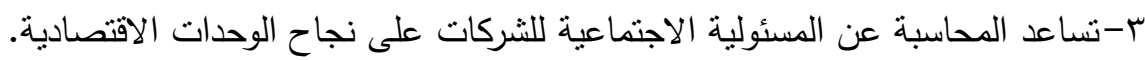

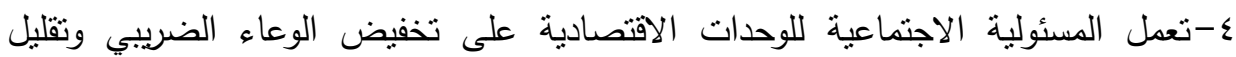

$$
\text { الثعور بعدوانية الضريبة لاى الممولين. }
$$

ه-القوائم المالية التي تتشرها الوحدات الاقتصادية في البيئة الصصرية تعتبر قوائم قاصرة وغير مكتملة نظراً لعدم إدخال البعد الاجتماعي ضمن تلكات التهات القوائم.

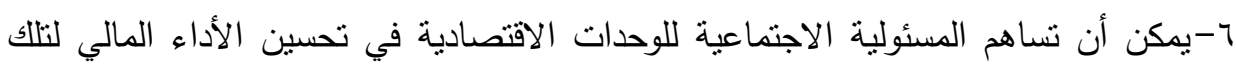

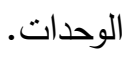
V- أن الدسئولية الاجتماعية دائماً ما تحتاج دعماً وقت الثدائد والأزمات وليس تراجعاً وبالتالي تعمل المسئولية الاجتماعية على الحد من الأزمات المالية العالمية. (محمد عبد الله محمود

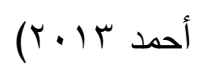




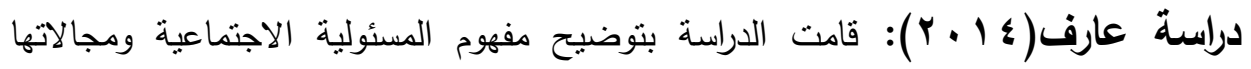

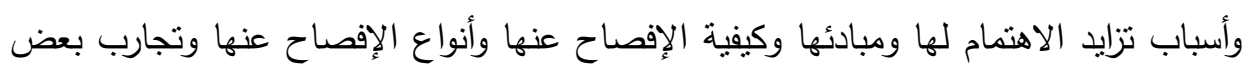

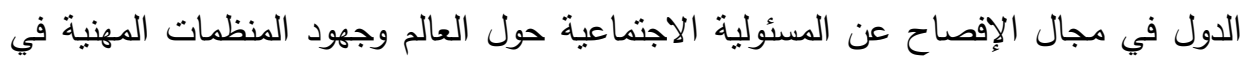
دعم الإفصاح عن المسئولية الاجتماعية، وتوصلت الدراسة إلى إطار مقترح لزيادة فعالية الإفصاح عن المسئولية الاجتماعية من خلال تقرير مفصل تضمن:

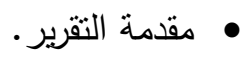
• • مؤشرات اقتصادية عامة.

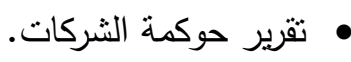

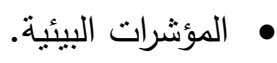

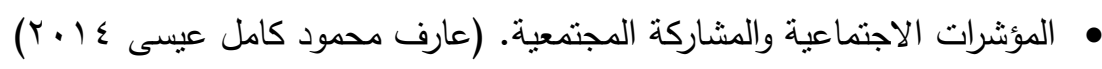
دراسة توفيق(ع ا ب ب): هدفت الدراسة إلى تحليل محددات وحوافز قيام الإدارة العليا للشركات المقيدة بالبورصة المصرية بالتقرير عن المسئولية الاجتماعية لها ومن ثم إدراجها بالمؤشر المصري للمسئولية الاجتماعية.

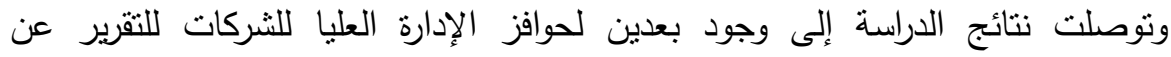
المسئولية الاجتماعية لها وهما البعد الاقتصادي والبعد السلوكي، وأن تبني الإدارة العليا للثركات

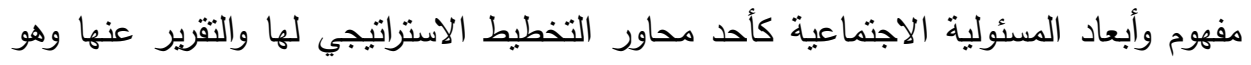

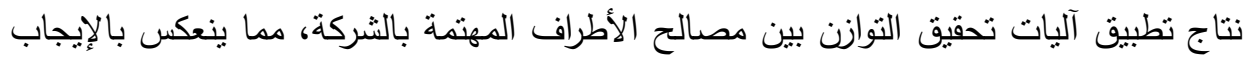
على الأداء المالي سواء في الأجل القصير أو الأجل الطويل. (د. علاء الدين توفيق إبراهيم

دراسة إدريس(0) Y Y): هدف البحث إلى بيان أهمية وطرق الإفصاح عن المسئولية الاجتماعية في القوائم المالية بغرض زيادة قيمة المنشأة وبيان أثز ذلك على الأداء المالي ويتم تحقيق هذا الهرف من خلال مجموعة من الأهداف الفرعية التالية: 
1-التعرف على طرق ووسائل الإفصاح عن المسئولية الاجتماعية في التقارير المالية ومدى

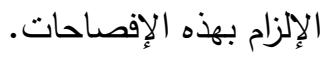

r-تفسير العلاقة بين آليات الحوكمة للشركات وإفصاحات المسئولية الاجتماعية. ب-وضع القواعد العامة للإفصاح عن المسئولية الاجتماعية في الثركات الليبية.

ع-بيان العلاقة المنبادلة بين الأداء المالي والمسئولية الاجتماعية والأخلاقية والتتمية المستدامة.

وقد توصلت الدراسة إلى عدة نتائج وهي:.

1-التوجه نحو نتظيم محاسبي محكم في بيئة الأعمال الليبية يتضمن الإفصاح والثفافية بصفة

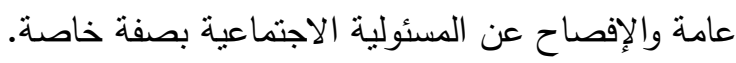

r-تشجيع الثركات الليبية على الالتزام بآليات حوكمة الثركات والأداء المتوازن من خلاهله مراعاة الجوانب الأخلاقية والبيئية والاجتماعية.

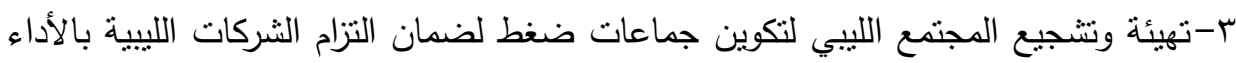
الاجتماعي.

ع-العمل على استخدام الوازع الديني الأخلاقي في ليييا لضمان الالتزام بالجوانب الأخلاقية والاجتماعية والبيئية للشركات الليبية.

ه- العمل على إلزام مراجع الحسابات الخارجي للثركات الليبية على مراجعة الأداء الاجتماعي اللئي للشركات الليبية وتقديم تقرير بذلك.

צ-بيان الدور الذي يمكن أن تلعبه كافة الأطراف في المجتمع الليبي في وضع الحوافز

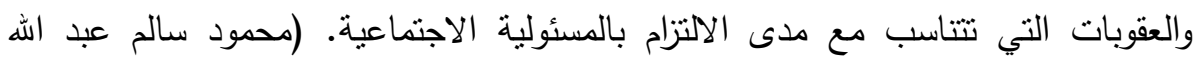

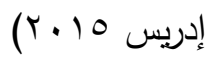

دراسة محروس(Y 1 • (Y): هدف البحث إلى دراسة انعكاسات الإفصاح عن الأداء الاجتماعي على القدرة التتبؤية للمعلومات المحاسبية ويتم ذلك من خلال عدة أهداف فرعية وهي:.

1-عرض الأدب المحاسبي والجوانب الفكرية لتحديد الإطار المفاهيمي لكل من الأداء الاجنماعي وبيان مفاهيم المصطلحات التي تختص بوصف علاقة المنشأة بالمجتمع.

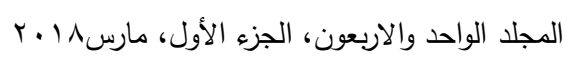


r-التوصل إلى مفهوم استراتيجية المسئولية الاجتماعية التي ينت من خلالها الإفصاح عن

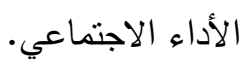

r- التعرف على علاقة الإفصاح عن الأداء الاجتماعي بالأداء المالي بمنشآت الأعمال.

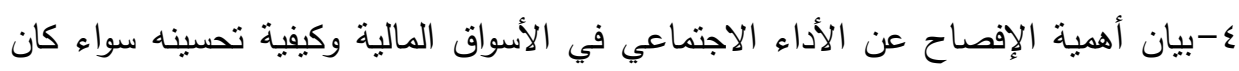
هذا الإفصاح اختياري أو إلزامي.

ه-بيان مداخل تأثثر الإفصاح عن الأداء الاجتماعي وبيان انعكاس ذلك على القدرة التتبؤية

$$
\text { للمعلومات المحاسبية. }
$$

\section{وقا توصلت الدراسة لعدة نتائج هي:.}

1-يعتبر الإفصاح عن الأداء الاجتماعي أحد الإفصاحات الاختيارية عن المعلومات الغير

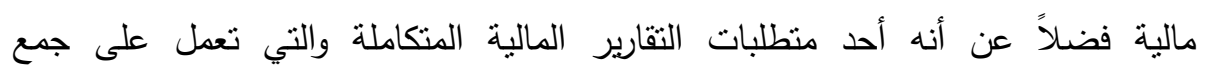
المعلومات المالية والغير مالية لمزيد من الثفافية حول أداء منشآت الأعمال.

r-تعتبر المسئولية الاجتماعية حلقة الوصل بين القيام بالأداء الاجتماعي وبين الإفصاح عنده.

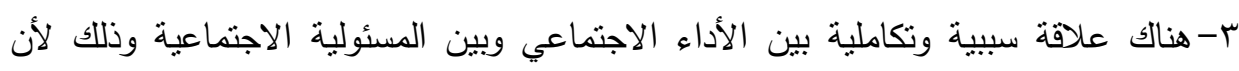
القيام بالأداء الاجتماعي لن يتم إلا بدافع التزام المنشأة بتطبيق مبادئ المسئولية الاجتماعية.

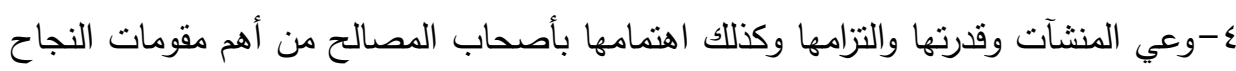
للقيام بالمسئولية الاجتماعية للشركات. ه-الأداء الاجتماعي الذي تقوم به المنشأة بشكل جيد يعتبر استثمار يعمل على زيادة قيمة

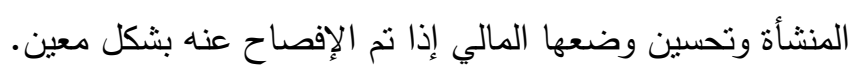

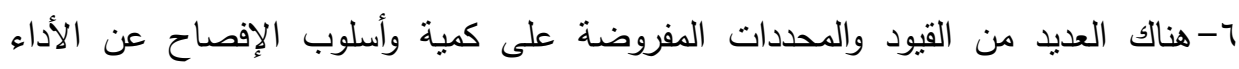

$$
\text { الاجتماعي. }
$$

V-يعتبر الإفصاح عن الأداء الاجتماعي أحد العوامل المؤثرة على سير العمل في الأسواق المختلفة. ^-أن الإفصاح عن الأداء الاجتماعي له تأثثر على تحسين الأداء المالي. (منى سعيد

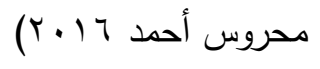




\section{الإفصاح المحاسبي عن المسئولية الاجتماعية في الوحدات}

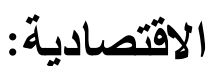

مفهوم المسئولية الاجتماعية: نؤكد الكتابات على عدم وجود تعريف موحد وثابت للمسئولية

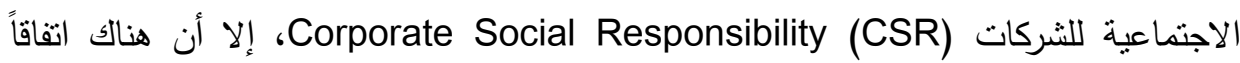
على أربع محاور رئيسية تدور حولها المسئولية الاجتماعية للشركات وهي محاربة الفساد،

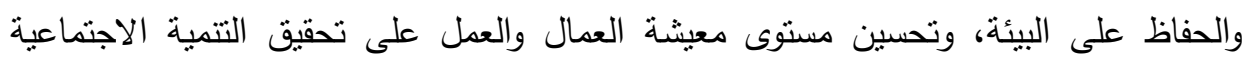
المستدامة، وعلى الثركات إيجاد السبل المناسبة لنقييم أداء الثركات فيما يتعلق بالمسئولية ولئه الاجتماعية، كما أنه يجب أن تتجاوز المسئولية الاجتماعية التبرعات، وأن تأتي في إطار بناء

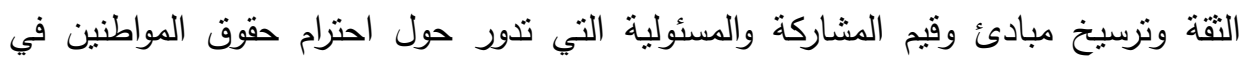
المتمع الذي تعمل فيه تلك الشركات واحترام حقوق العاملين في الثركات، والحفاظ على البيئة

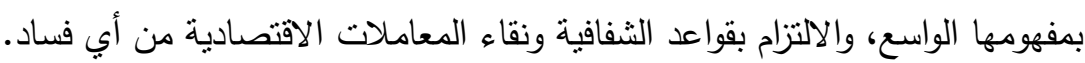

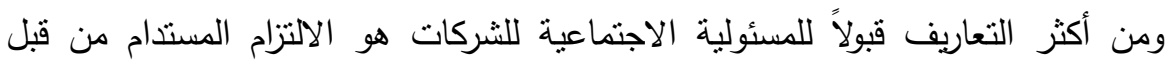

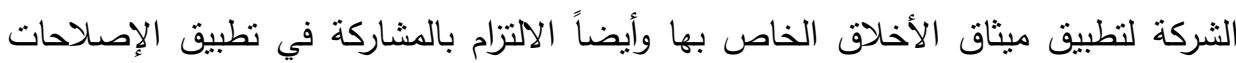
للمجتمع من خلال تحسين مستوى معيشة الأفراد والعمل على زيادة وعيهم لأهمية المسئولية

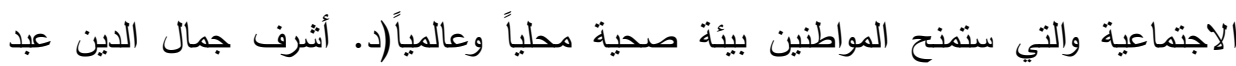

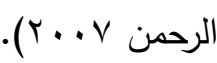

وعرف مجلس الأعمال العالمي للتتمية المستدامة (WBCSD, 1999) المسئولية

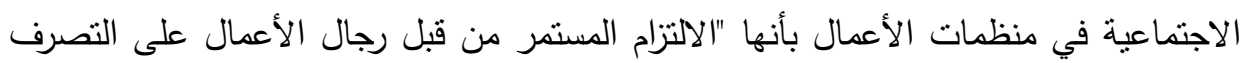

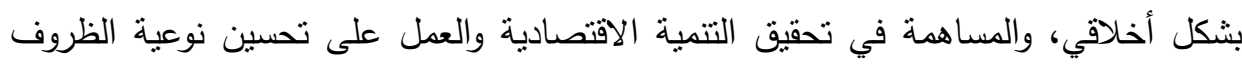
المعيثية للقوى العاملة وعائلاتهم، وكذلك المجنمع المحلي والمجتمع ككل".

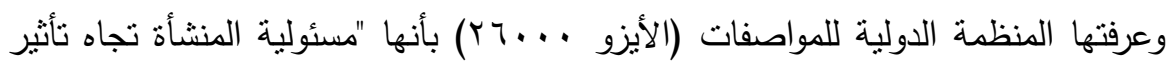

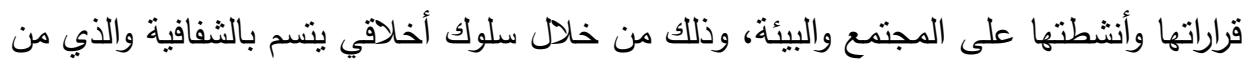
شأنه: المساهمة في التتمية المستدامة منضمنة صحة وانئة ورخاء المجنمع، والأخذ في الاعتبار

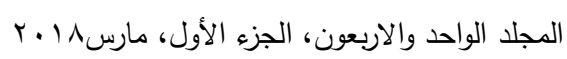


توقعات الأطراف المعنية، والتماشي مع القوانين المطبقة ومعايير السلوك الدولية، والتكامل بين المنشأة وممارستها المختلفة من خلال العلاقة بينهما". وتثير الباحثة بأن المفهومين السابقين أثنارا إلى أن المسئولية الاجتماعية تعكس التزاماً

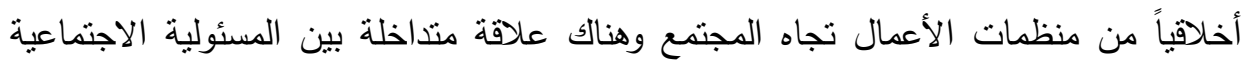
للشركة وأخلاقيات الأعمال، حيث إن المسئولية الأخلاقية (Ethical Responsibility) هي

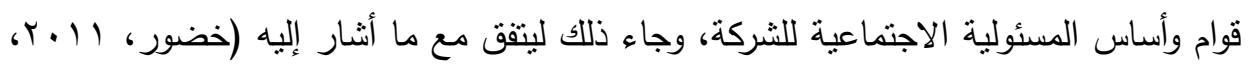

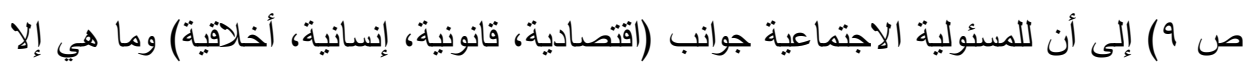
طريقة عمل للمؤسسات تضفي الصبغة الأخلاقية على نشاطتها وتكون القضايا البيئية والاجتماعية جزء من سياستها وممارستها.

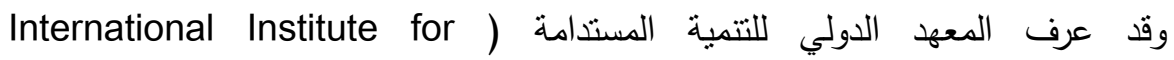
(Sustainable Development-HSD

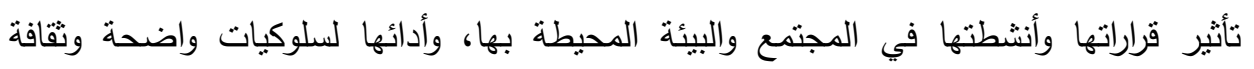

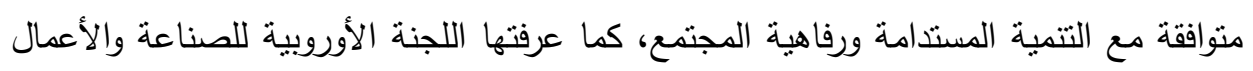
بأنها ذلك المفهوم الهادف إلى إحداث تكامل بين اهتمامات الثركة الاجتماعية والبيئية وأعمالها الربحية، وأن تتبع أعمالها أساساً من التطوع والمبادرة التي تنثل التزاماً قانونياً وأخلاقياً تجاه التهاه

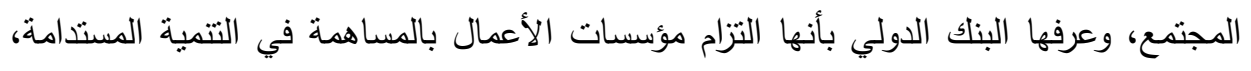

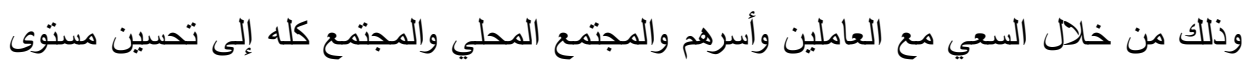

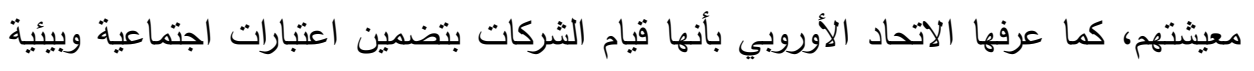
في أعمالها وتفاعلها مع أصحاب المصالح على نحو تطوعي وعرفتها المنظمة الدولية للمسئولية

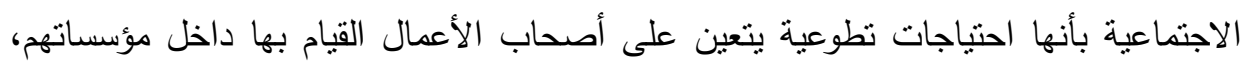

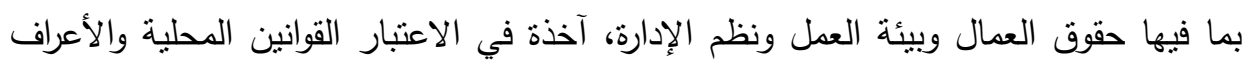

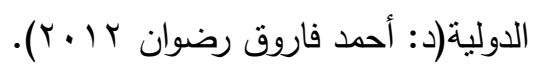


اتجاهات المسئولية الاجتماعية: تتجاوز المسئولية الاجتماعية للشركات إطار يحدد توجهاتها، حيث يحظى هذا الإطار باهتمام كبير، حيث يعتبر هذا الإطار بمثابة البناء الذي تقوم عليه

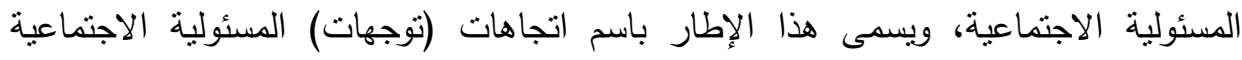

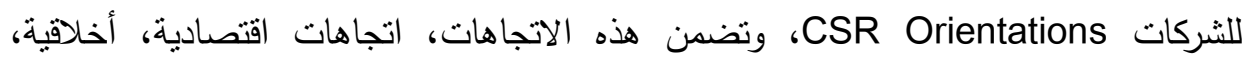
قانونية، اختيارية.

• الاتجاهات الاقتصادية Economic Orientations :وتتضمن الاتجاهات الاقتصادية في أنه يجب على المنظمات أن تكون مربحة ومنتجة لتلبية منطلبات المجتمع من خلال

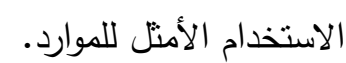

• الاتجاهات الأخلاقية:Ethical Orientations: :يفترض هذا التوجه في أنه يجب على التى المنظمات أن تتبع قواعد ومعايير غير مكتوبة، شائعة الاستخدام، وملائمة، حيث تعتبر مثل هن تلاك القواعد والمعايير أمراً حيوياً لنجاح المنظمات، كما أن المنظمات التي تعمل أساساً في

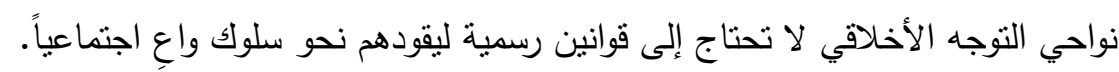

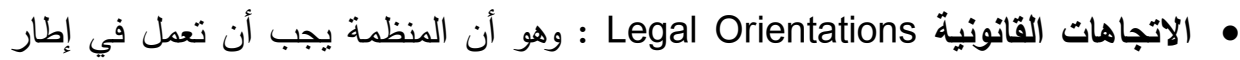
قانوني، حيث إن أي مجهودات لتلبية المنطلبات المالية والاقتصادية للمنظمة يجب أن أنكون مقبولة قانوناً. • الاتجاهات الاختيارية Discretionary Orientations :وهو نوقع المجتمع من المنظمات القيام بأعمال مساهمات وأعمال تطوعية للأنشطة الخيرية والإنسانية. وحيث إن الأساس الذي تقوم عليه فلسفة الالتزام بتطبيق محاسبة المسئولية الاجتماعية،

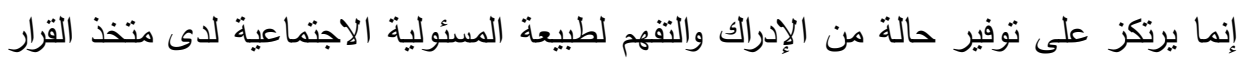

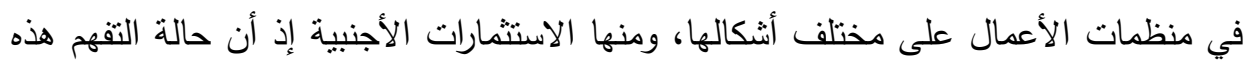

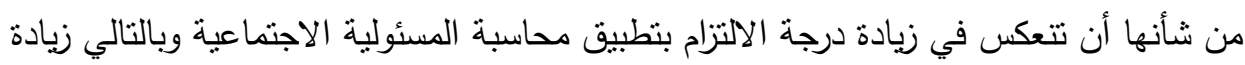

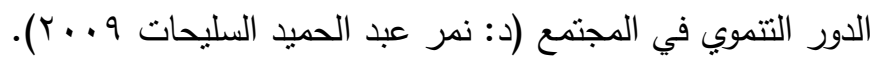


المسئولية الاجتماعية ومنظمة الأيزو ISO: في أكتوبر (د: علي محمود موسى r ب ب)

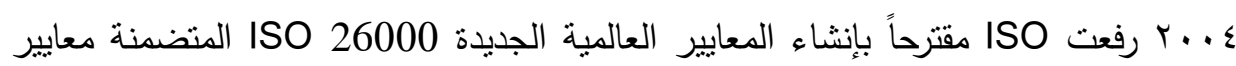

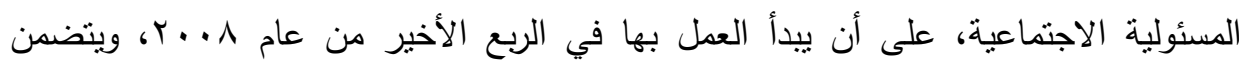

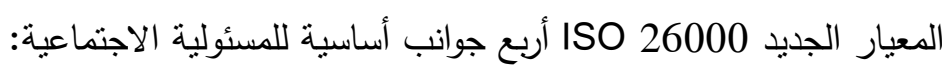

$$
\begin{aligned}
& \text { • الجانب الثقافي. } \\
& \text { • الجانب الاجتماعي الحضاري. } \\
& \text { • الجانب البيئي والقانوني. } \\
& \text { • شروط متعلقة بالتتمية الاقتصادية. }
\end{aligned}
$$

كما أن منظمة الأيزو تعطي الحق للاول المتحفظة على المواصفة بيناء مواصفة محلية

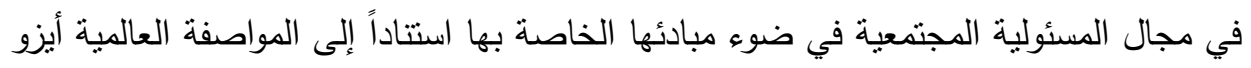

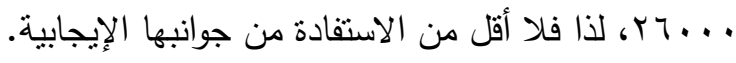

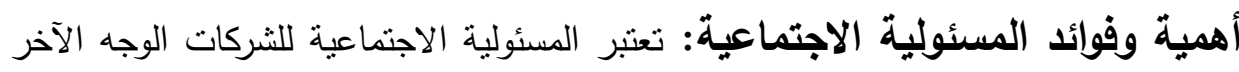
لمبدأ تحقيق أقصى الأرباح، وشهدت الشركات والدول خلال نصف القرن الماضي والعقد الأول

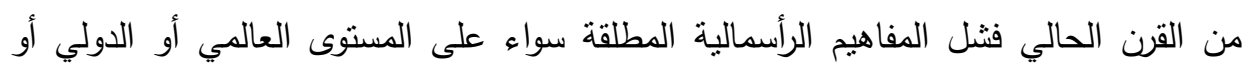
المحلي، مثال ذلك خسائر الثركات وإفلاس البنوك واتساع الفجوة بين الدول الغنية والدول الفقيرة

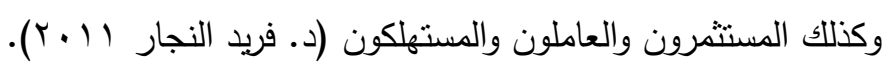
لذلك أصبح من الضروري اهنمام الثركات بالمسئولية الاجتماعية في ثوبها الجديد الذي وني يستخدم الحوكمة ومنلث المسئولية الاجتماعية والذي يضم أيضاً حماية المستهلك وتمثيل الثركة فئن أمام المجتمع المحيط؛ وكذللك الذي يحقق رضا أصحاب المصالح المشتركة بغرض تفعيل قرارات مشاركة الثركات في رفاهية المجتمع، حيث من الضروري الربط بين كل من المسئولية الاجتماعية للشركات وحماية المستهلك وتمثيل الثركات أمام المجتمع المحيط.

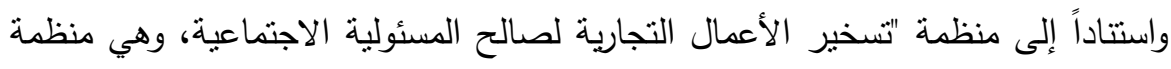
أعمال تجارية تتخذ من الولايات المتحدة مقراً لها وتعمل من أجل النهوض بالقيم الاجتماعية،

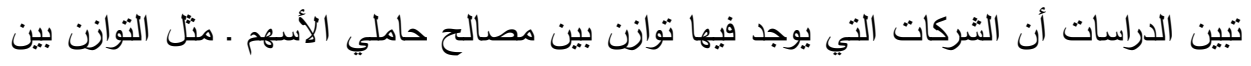
446

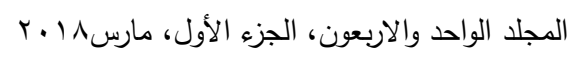


الإدارة، واليد العاملة والعملاء، حققت معدلات نمو ومعدلات لتوليد العمالة تفوق الثركات الأخرى بنسبة أربعة أضعاف وثمانية أضعاف على التوالي، وفي الوقت نفسه، أثنتت الدراسات

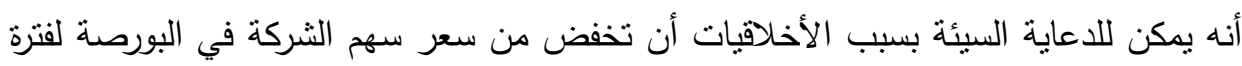

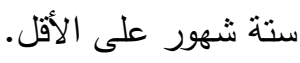

ومن بين الفوائد التي تجنيها الثركات ذات الممارسات المسئولية اجتماعياً تقليص تكاليف

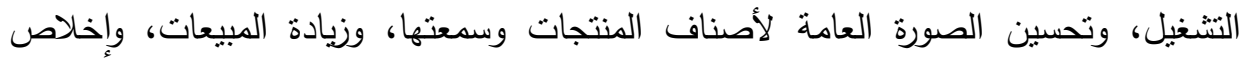

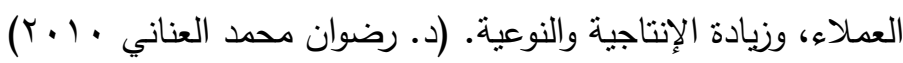

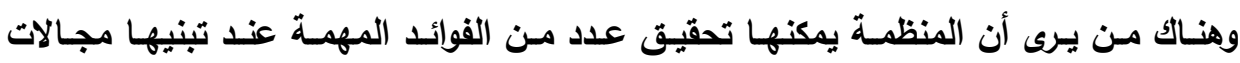

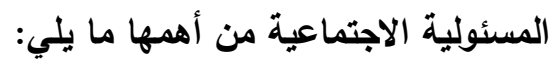
• تعزيز ولاء الموظفين وروحهم المعنوية، وتحسين سلامة العاملين والاهتمام بحقوقهم هن

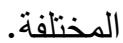
• تحسين اعتمادية ونزاهة التعاملات من خلال المنافسة العادلة، وانعدام الفساد. • • • • • • • المساهمة في حيوية المنظمة على المدى الطويل عن طريق تعزيز استدامة الموارد الطبيعية

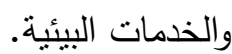
• المساهمة في المصلحة العامة، وتعزيز دور المجتمع المدني (م: عوض سالم

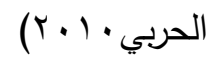

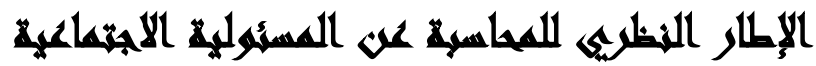

ظهر مفهوم محاسبة المسئولية الاجتماعية social Responsibility Accounting في الفكر المحاسبي في بداية العقد السادس من القرن العشرين، حيث برزت هذه المحاسبة نتيجة زيادة حجم وقدرات الوحدات المحاسبية، لاسيما الثركات المساهمة العامة. 
وقد أدى ذلك إلى زيادة الاهتمام بالمسئولية الاجتماعية للمشروع من قبل مجموعات

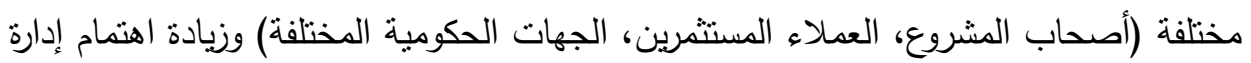
المشروع ومتخذي القرارات والجهات الحكومية بقيام المشروع بالأنشطة الاجتماعية المنوطة به. وتعتبر المحاسبة الاجتماعية من أحدث مراحل تطور الفكر المحاسبي، ويرتبط نطورها

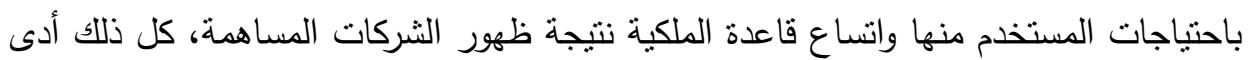

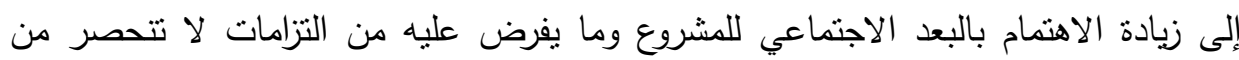

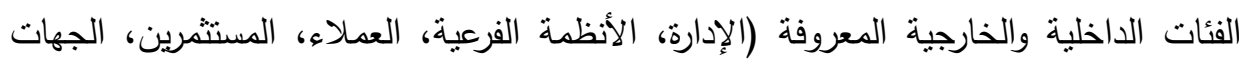
الحكومية) بل إلى أبعاد اقتصادية واجتماعية (إياد محمد عودة ^ ... ب).

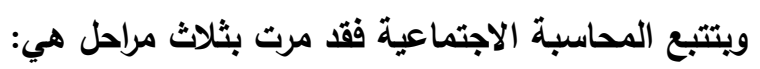

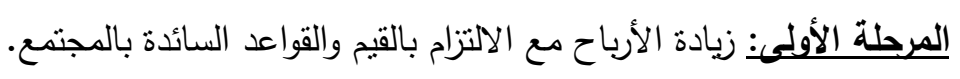

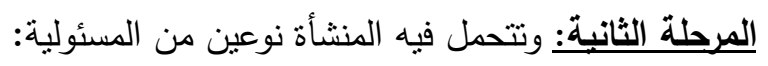
أ- مسئولية خاصة: تحقيق الأرباح لأصحاب المنشأة.

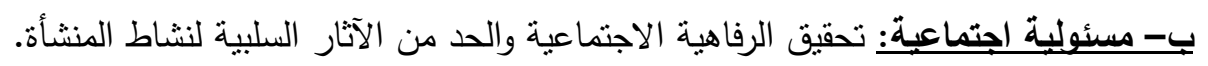

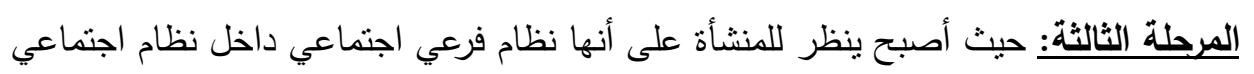

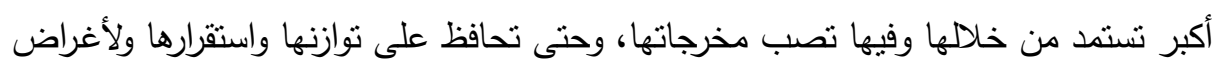

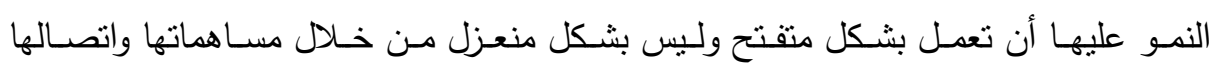
بالمجتمع بشكل مباشر •

حيث أسهمت المحاسبة الاجتماعية في العديد من الانتقادات الموجهة للمحاسبة التقليدية

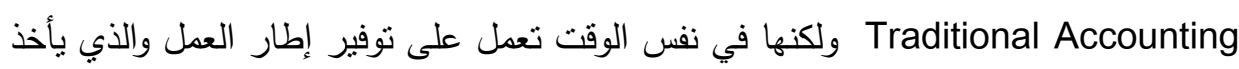
في الحسبان مجموعة أوسع من العناصر داخل العمل المحاسبي، وذلك لأن المحاسبة الاجتماعية تعتبر بمثابة مصطلح أوسع وأثنمل يحتوي على مجموعة متتوعة من النماذج الجان المحاسبية البديلة لها مثل محاسبة القيمة المضافة، المحاسبة البيئية، ومحاسبة الاستدامة

(Laurie Ingrid Mook 2007) 
وتهدف المحاسبة عن المسئولية الاجتماعية إلى إعداد التقارير عن الأنشطة التي تقوم بها

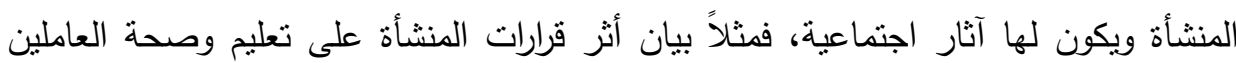

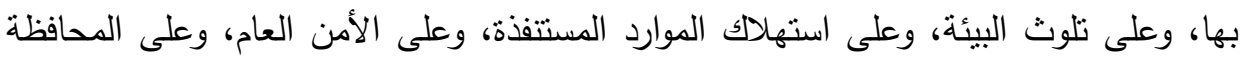

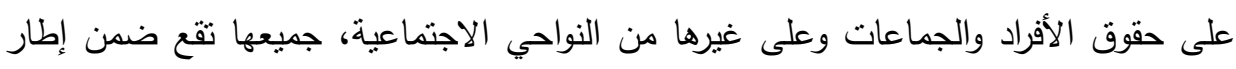
المحاسبة عن المسئولية الاجتماعية.

إلا أن هناك وجهة نظر ترى أن الثقارير البيئية للشركات يمكن أن تعمل على توفير الثئه

المزيدمن البيانات عن المحاسبة الاجنماعية(Martin Freedman and A. J 2004). We believe that even though the environmental reporting firms will provide more social accounting data.

\section{الإفصاح المحاسبي عن معلومات المسئولية الاجتماعية للوحدات الاقتصادية:} ظهرت دراسات محاسبية عديدة تؤكد على أهمية الإفصاح عن مدى وفاء المنشأة بمسئوليتها الاجتماعية الذي ينبغي أن يكون على نفس درجة أهمية الإفصاح عن المسئولية الاقتصادية كأساس لتحقيق الرفاهية الاجتماعية، ولقد أوضحت هذه الدراسات أن تحسين مجالات الإفصاح المحاسبي وتوسيع مضمونه يقتضي عدم تركيزه على المعلومات التي تعكس العمليات المالية

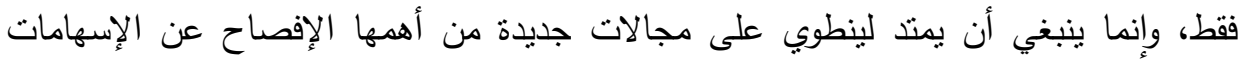

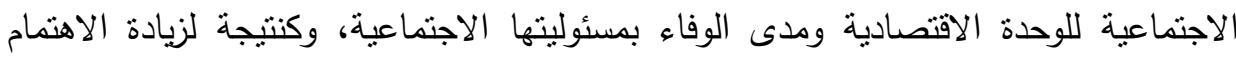

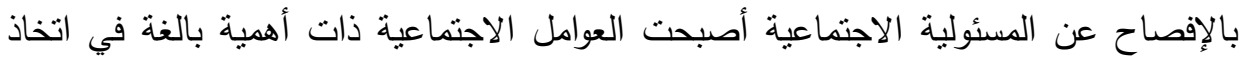
القرارات وبخاصة قرارات الاستثمار، فقد أوضحت بعض الدراسات في هذا المجال أن نسبة كبيرة

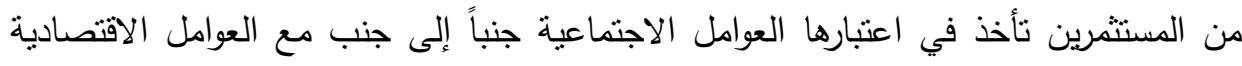

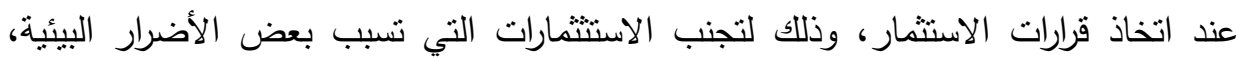

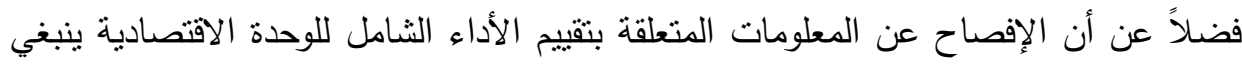

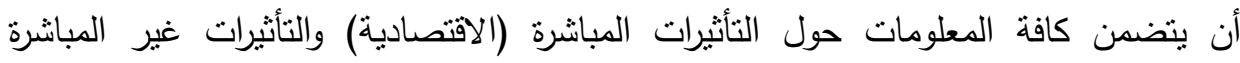

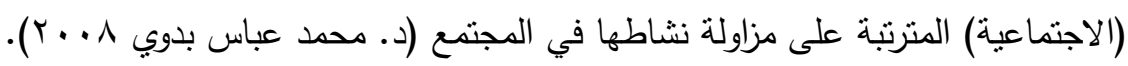


وعلى الرغم من الاهتمام المتزايد بالإفصاح عن الأداء الاجتماعي للوحدات الاقتصادية،

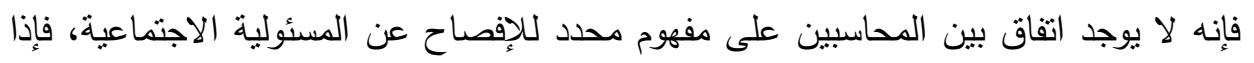
كان الإفصاح المحاسبي يتطلب أولاً إعداد وتجهيز المعلومات التي يتم الإفصاح عنها تمهيداً لنقلها إلى مجموعة الأطراف ذات الاهتمام بها، فإن استيعاب نطاق الوظائف المحاسبية

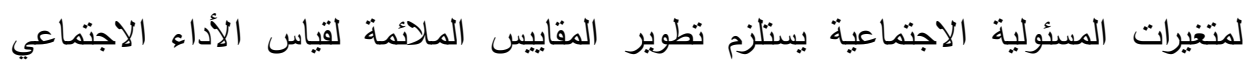

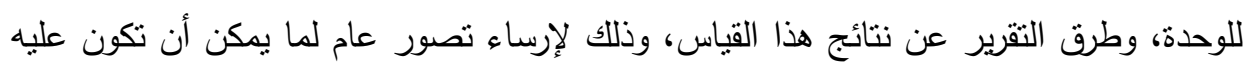

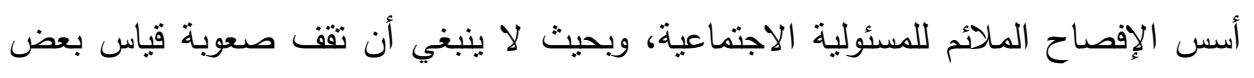

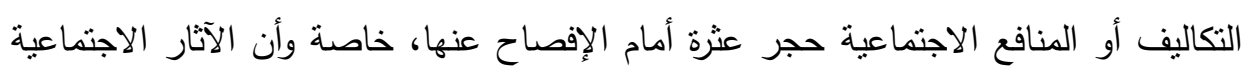

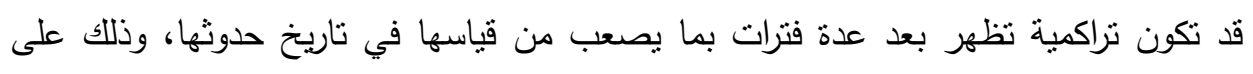

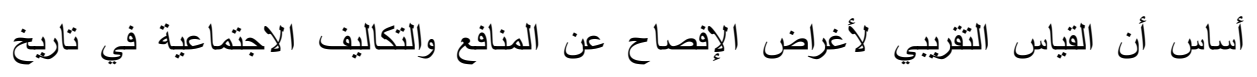
حدوثها يكون أفضل من عدم قياسها على الإطلاق، وذللك للإفصاح عن مساهمة الوحدة الإنة الاقتصادية في تحقيق الرفاهية الاجتماعية، كما أن الإفصاح عن محاسبة المسئولية الاجتماعية

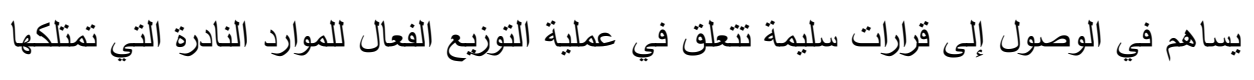

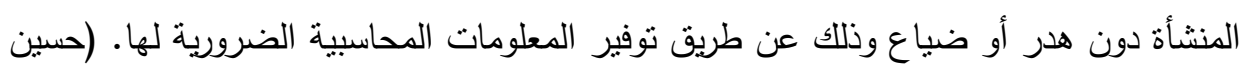

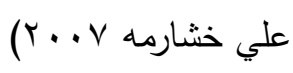

\section{مجالات الإفصاح عن أنشطة المسئولية الاجتماعية:نتيجة للضغوط الاجتماعية} للمسئولية الاجتماعية للشركات أصبح الإفصاح الاجتماعي مألوفاً بشكل تدريجي، حيث أصبح

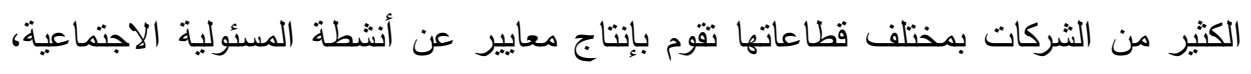

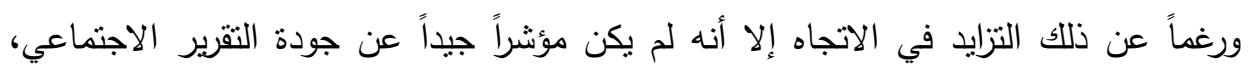

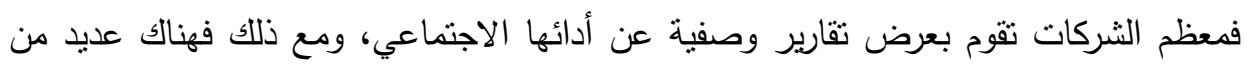

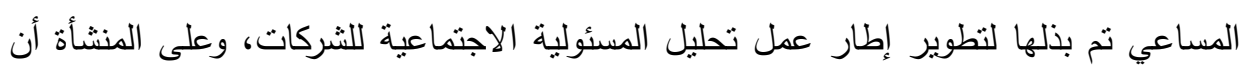

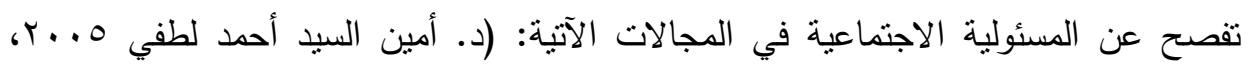

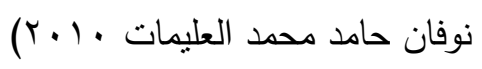


تنمية الموارد البشرية (العاملين) ويتضمن بعض أو كل من الآتي:

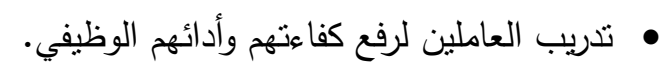
• • • • • ثفير الرعاية والتأمين الصحي للعاملين، ولأسرهم.

• توفير مسكن مناسب للعاملين، ووسائل مواصلات وتتقل مريحة.

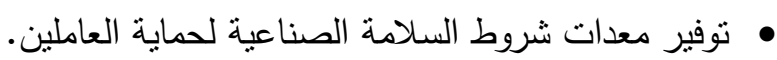
• تهيئة ظروف العمل المناسبة وأوقات للراحة، وإنشاء فرق رياضية. • تشغيل الأقليات (إن وجدت).

تحسين جودة المنتج وحماية المستهلك ويتضمن بعض أو كل الأشكال الآتية: • مطابقة السلع للجودة ومعايير الأمان والسلامة. • احتواء المنتجات على إرشادات واضحة تنين المحتويات واستخدامها والصلاحية. • • المحافظة على أساليب حماية المستهلك.

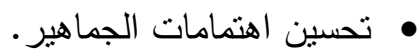
م الاهتمام بشكاوى واقتراحات المستهلكين. مالإنفاق في ميادين خدمة المستهلك.

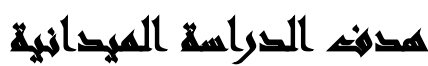

حيث تهذف الدراسة الميدانية إلى تحقيق أمرين هما:الأمر الأول: اختبار فروض الدراسة.

الأمر الثاني: استطلاع أراء ممارسي المهنة الممثلين في الإدارة العليا ومتخذي القرارات والمحاسبين والمراجعين ومديري شركات البترول [تشركة بترول خليج السويس (جابكو) - شركة خالدة للبترول] والسادة أعضاء هيئة التدريس في الجامعات حول مدى وضوح مفهوم المحاسبة الاجتماعية ومدى تحقيق المسئولية الاجتماعية للوحدات الاقتصادية من خلال الإفصاح عنها لهاه بالتقارير والقوائم المالية والتي تخدم أصحاب المصالح ومتخذي القرارات. 


\section{مجتمع التراسلة}

يشمل مجتمع الدراسة كلاً من السادة أعضاء هيئة التدريس بالجامعات المصرية والسادة

$$
\text { العاملين في قطاع شركات البترول. }
$$

\section{xaly}

اثتملت عينة الدراسة على عينة مكونة من 10 مفردة من السادة أعضاء هيئة التدريس بالجامعات والسادة العاملين بشركات البترول [ثركة بترول خليج السويس (جابكو) - شركة

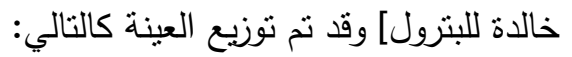
جدول رقم(1 ):يوضح توزيع عينة البحث حسب الجهة

\begin{tabular}{|c|c|c|c|}
\hline | النسبة \% & العدد & الجهة & م \\
\hline \%rr,r & ا & السادة أعضاء هيئة التذريس بالجامعات & 1 \\
\hline \%чr, r & 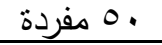 & شركة بترول خليج السويس (جابكو) & Y \\
\hline$\% r r, r$ & • 0 مفردة & شركة خالدة للبترول & $\mu$ \\
\hline$\% 1 \ldots$ & • 10 مفردة & آلإجمالى & \\
\hline
\end{tabular}

يتضح من الجدول السابق بأن الباحثون قاموا بتوزيع قائمة الاستقصاء على السادة أعضاء

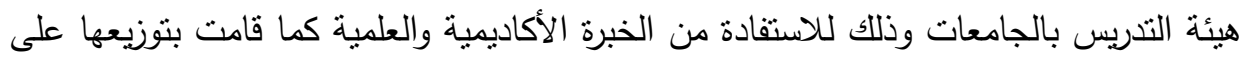
شركتي [شركة بترول خليج السويس (جابكو) - شركة خالدة للبترول] لأن هذا القطاع هو لهائ الأقرب إلى موضوع الدراسة.

\section{أسالا بمع البريلاماته}

لجمع بيانات الدراسة الميدانية وتحليلها مر الباحثون بالخطوات التالية:

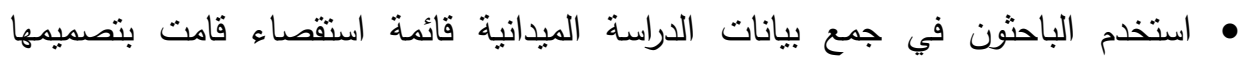

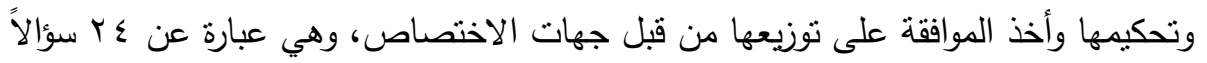
تتفق مع أهداف البحث، وتساعد على اختبار فروضه.

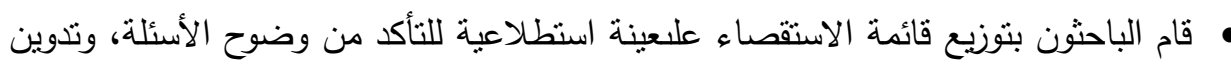
ملاحظات المستجييين. 
• بعد أخذ ملاحظات المستجيبين في الاعتبار قام الباحثن بصياغة القائمة في صورتها النهائية، وتوزيعها على عينة البحث.

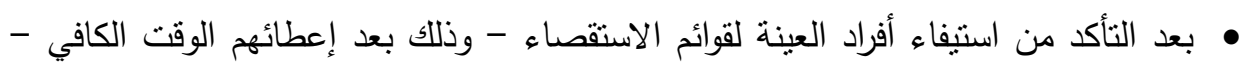
قام الباحثون بجمع تللك القوائم من المستجيبين.

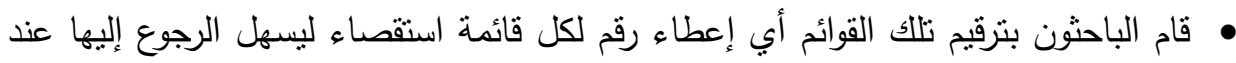

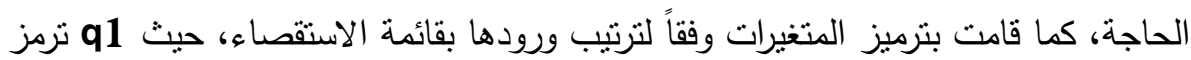
للسؤال الأول، q2 ترمز للسؤال الثاني،و24 ترمز للسؤال الرابع والعشرين.

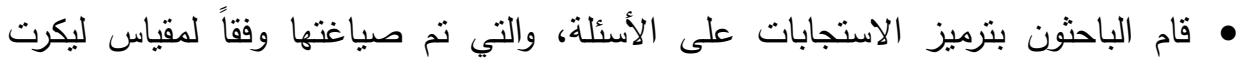

\begin{tabular}{|c|c|c|c|c|}
\hline \multicolumn{5}{|c|}{ الترتيبي الخماسي وفقا لما يلي: } \\
\hline معارض بشدة & معارض & 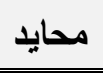 & موافق & موافق تماماً \\
\hline 1 & $r$ & $r$ & $\varepsilon$ & 0 \\
\hline
\end{tabular}

وتحليلها.

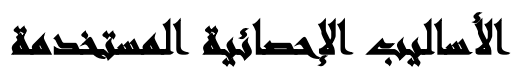

قام الباحثون باختبار صلاحية بيانات الدراسة للتحليل الإحصائي وذللك بإجراء اختبار

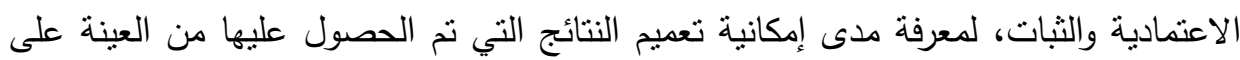

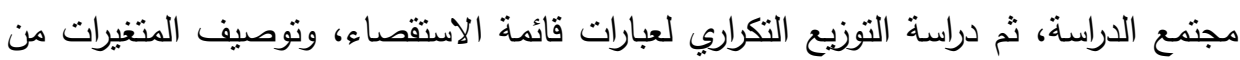

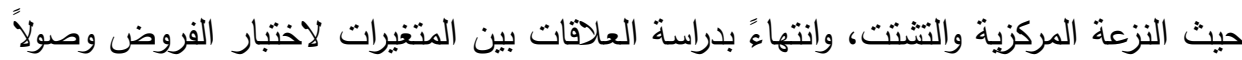

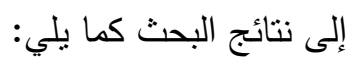
• مقياس الاعتمادية:Reliability: وذلك من خلال مقياس ألفا Cronbatch's Alphaوهو

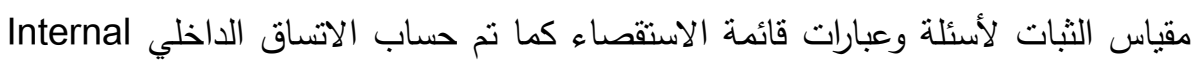
Consistency 
وذلك لهعرفة مدى الوثوقية فى استجابات عينة البحث على أسئلة قائمة الاستقصاء، ومدى إمكانية تعميم نتائجها على مجتمع الدراسة.

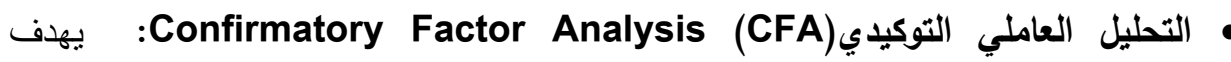
التحليل العاملي الى التحقق من صحة تمثيل العبارات للعوامل المؤثرة (أي التحقق من صدق تمثيل العبارات) لأبعادالدراسة. • التكرارات والنسب المئوية Frequency Tables: حيث ييين هذا الأسلوب أعداد استجابات عينة البحث على أسئلة قائمة الاستقصاء، والأوزان النسبية لكل استجابة.

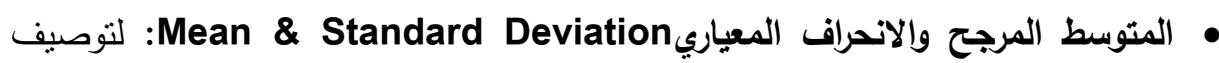
متغيرات الدراسة من حيث النزعة المركزية والنتتت، مع زيادة الإيضاح باستخدام الرسوم لوريط البيانية Charts. • تحليل الانحدار البسيط Simple Regression: وذلك لاختبار فروض الدراسة ببناء نموذجي وضح العلاقة بين المتغير التابع والمتغير المستقل لكل فرض من فروض الدراسة.

\section{الختهار هروضه القراسمة}

اختبار الفرض الأول:لا نوجد علاقة معنوية بين التزام المنشأة بالمسئولية الاجتماعية ومنع التلوث في المياه والتربة. وقد تم اختبار هذا الفرض من خلال العلاقة بين التزام المنشأة بالمسئولية الاجتماعية

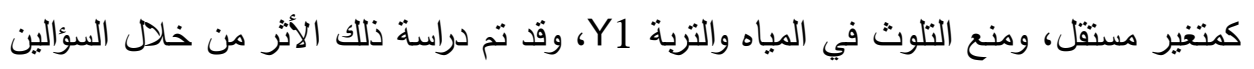

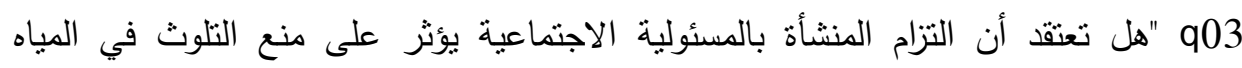

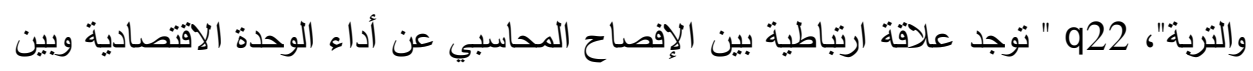

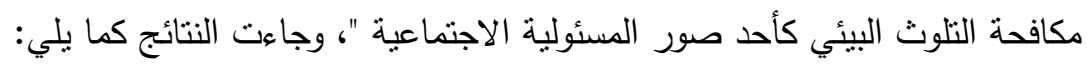

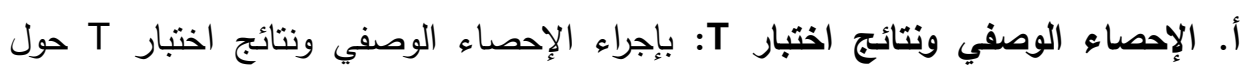

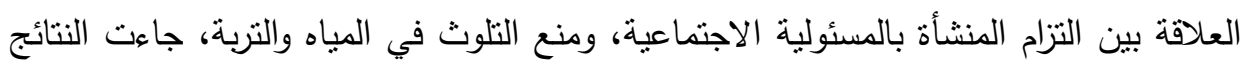
كما يلي: 
جدول رقم(1): الإحصاء الوصفي ونتائج اختبار T العلاقة بين التزام المنشأة بالمسئولية

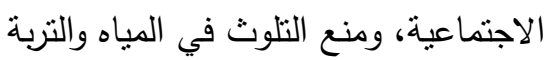

\begin{tabular}{|c|c|c|c|c|c|c|c|c|c|c|c|}
\hline المعنوية & قيمة T & الاختلافت \% & معياري & حسابي & تماماًُ & موافق & محايد & |معارض & | معارض & بيان & رالمتغز \\
\hline \multirow[b]{2}{*}{$\cdot, \cdots$} & \multirow{2}{*}{7,79} & \multirow{2}{*}{$r \cdot, V$} & \multirow{2}{*}{1,11} & \multirow{2}{*}{$r, \pi)$} & rq & $\varepsilon V$ & TI & Tr & 1 & عدد & \multirow{2}{*}{$q 03$} \\
\hline & & & & & $r \bar{r}, \cdot$ & $\mu, \mu$ & $r \cdot, V$ & $r, r$ & $\cdot, \mathrm{V}$ & $\%$ & \\
\hline \multirow{2}{*}{$\cdot, \ldots$} & \multirow{2}{*}{$\Gamma, \Sigma V$} & \multirow{2}{*}{ r } & \multirow{2}{*}{$1, \cdot r$} & \multirow{2}{*}{ T, } & 10 & 00 & $\varepsilon 1$ & $r \varepsilon$ & $\varepsilon$ & عدد & \multirow{2}{*}{$q 22$} \\
\hline & & & & & $1 \cdot, 1$ & $r q, q$ & $r v, 0$ & TY, & $r, V$ & $\%$ & \\
\hline
\end{tabular}

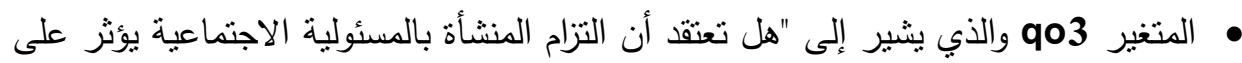
منع التلوث في المياه والتربة": بلغت نسبة الموافقة في الفئتين "موافق"، "موافق تماماً"

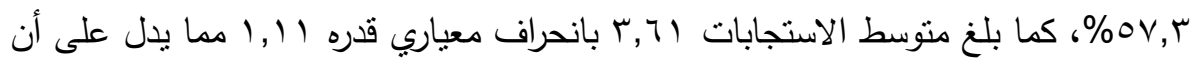

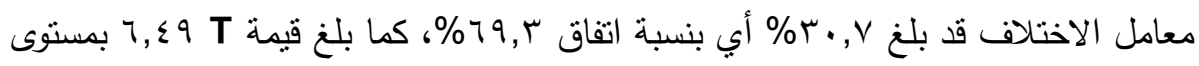

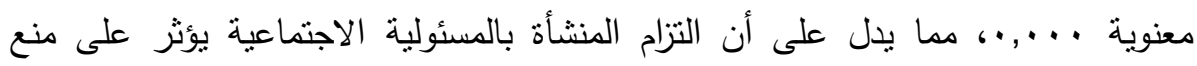

$$
\text { التلوث في المياه والتربة. }
$$

المتغير q22 والذي يشير إلى "توجد علاقة ارتباطية بين الإفصاح المحاسبي عن أداء

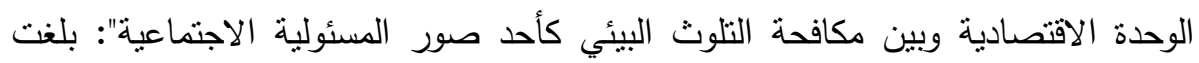

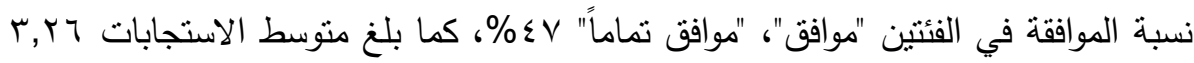

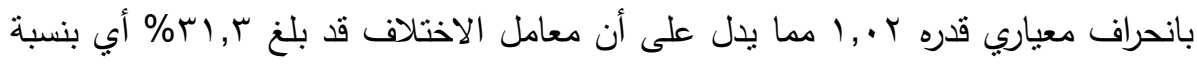

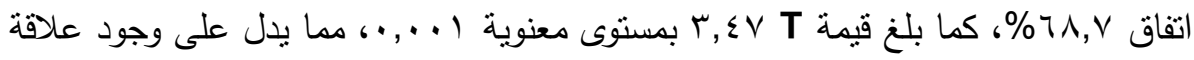
ارتباطية بين الإفصاح المحاسبي عن أداء الوحدة الاقتصادية وبين مكافحة التلوث البيئي كأحد صور المسئولية الاجتماعية. 
اختبار الفرض الثاني: لا توجد علاقة معنوية بين التزام المنشأة بالمسئولية الاجتماعية و مساهمة المنشأة في توفير فرص العمل.

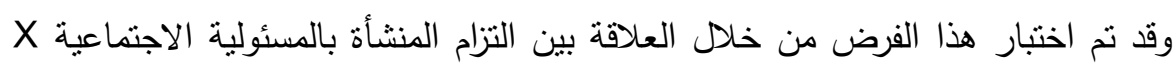

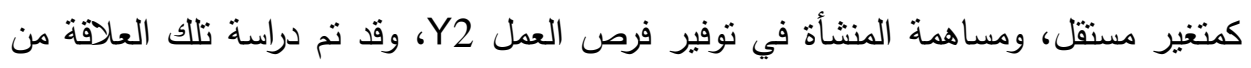

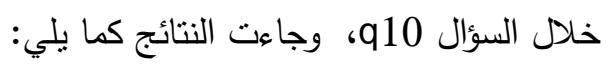

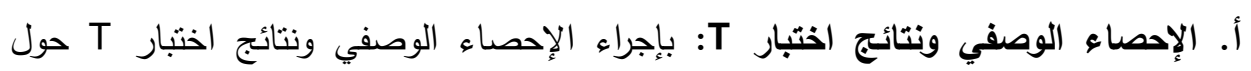

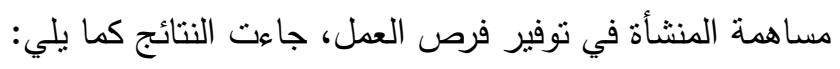

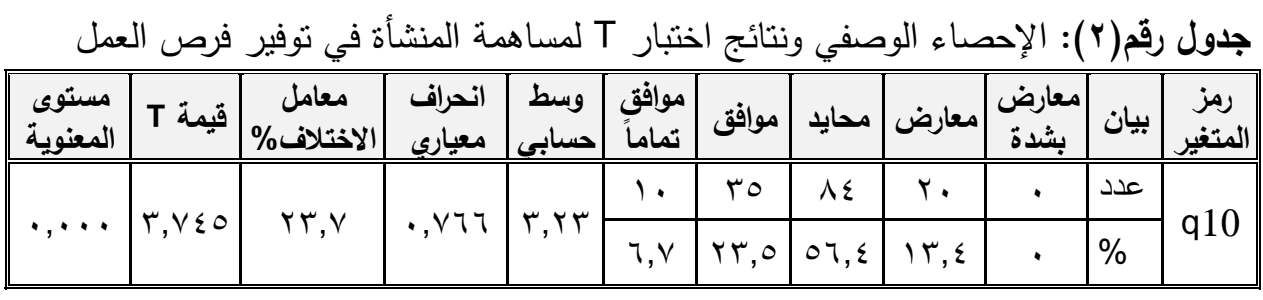
يتضح من الجدول ما يلي:

• المتغير q10 والذي يثير إلى "هل نساهم المنشأة في خلق فرص عمل جديدة لم تكن

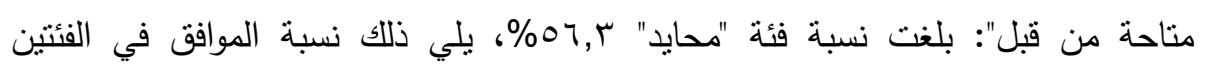

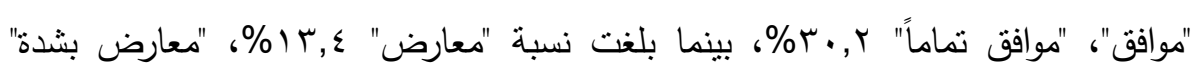

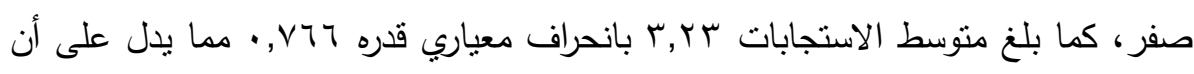

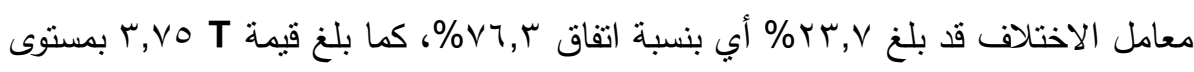

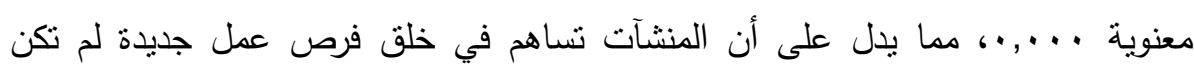
مناحة من قبل. اختبار الفرض الثالث: لا توجد علاقة معنوية بين التزام المنشأة بالمسئولية الاجتماعية وتوفير الرفاهية المادية للعاملين. وقد تم اختبار هذا الفرض من خلال العلاقة بين التزام المنشأة بالمسئولية الاجتماعية

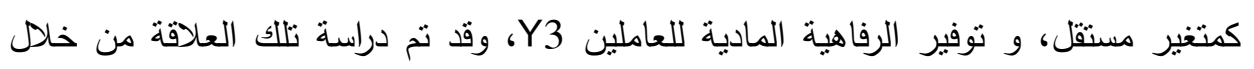

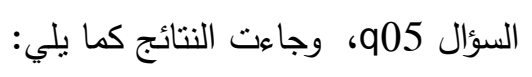


أ. الإحصاء الوصفي ونتائج اختبار T: بإجراء الإحصاء الوصفي ونتائج اختبار T حول التزام

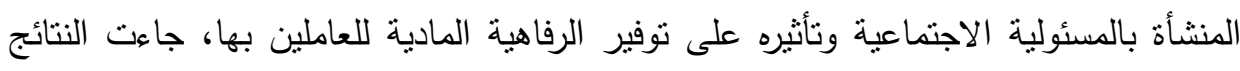
كما يلي: جدول رقم(T): الإحصاء الوصفي ونتائج اختبار T لتوفير الرفاهية المادية للعاملين

\begin{tabular}{|c|c|c|c|c|c|c|c|c|c|c|c|}
\hline المعنوية & قيمة T & الاختلافت & معياري & صسابي & تمواماً & موافق & محايد & معارض & بشدارض & بيان | & المتغز \\
\hline \multirow{2}{*}{$\cdot, \cdots$} & \multirow{2}{*}{$\Lambda, \vee>0$} & \multirow{2}{*}{$r, Y, V$} & \multirow{2}{*}{ זוג, • } & \multirow{2}{*}{$r, 01$} & IT & 19 & $\leqslant 7$ & 1. & $r$ & عدد & \multirow{2}{*}{ q05 } \\
\hline & & & & & $\Lambda,$. & $O r, V$ & $\Gamma \cdot, \tau$ & $7, \mathrm{~V}$ & $r,$. & $\%$ & \\
\hline
\end{tabular}

يتضح من الجدول ما يلي:

• المتغير q05 والذي يشير إلى "هل تعتقد أن التزام المنشأة بالمسئولية الاجتماعية سوف ئل

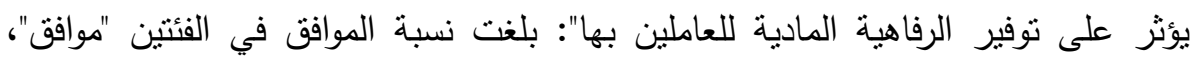

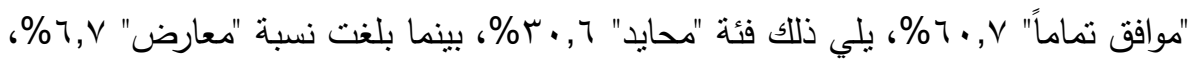

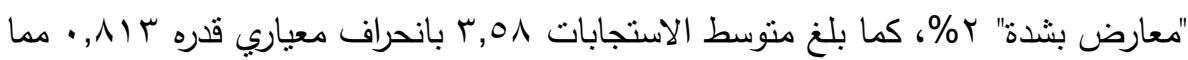

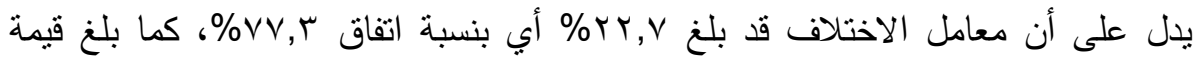

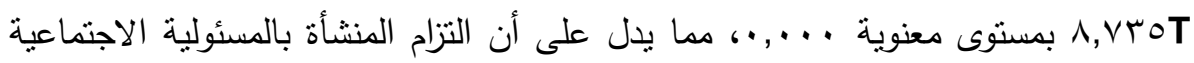
يؤثر على توفير الرفاهية المادية للعاملين يها.

\section{المتحائم}

نتائج خاصة بفرضيات الدراسة: نم رفض فروض الدراسة والني صيغت في صورة العدم، ونلك نظراً لجود علاقات ذات دلالة معنوية بين المتغير المستقل "إلتزام المنشأة بالمسئولية الاجتماعية" والمتغيرات التابعة كما يلي: الفرد 1-تم رفض الفرض الأول: "لا نوجد علاقة معنوية بين التزام المنشأة بالمسئولية الاجنماعية

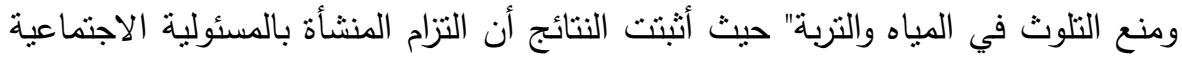

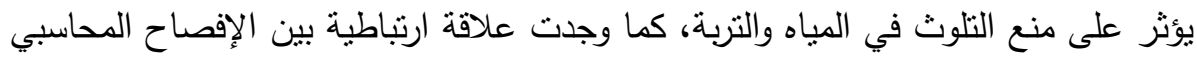

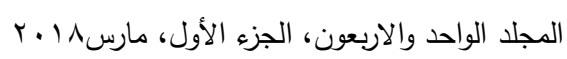


عن أداء الوحدة الاقتصادية وبين مكافحة التلوث البيئي كأحد صور المسئولية الاجتماعية، $\mathrm{Y} 1=-0.682+1.181 * \mathrm{X}+\varepsilon$ وأمكن تقدير معادلة انحدار أخذت الثكل التالي:

حيث:Y1 منع التلوث في المياه والتربة، التزام المنشأة بالمسئولية الاجتماعية، ع الخطأ

$$
\text { العشوائي. }
$$

r-تم رفض الفرض الثاني: "لاتوجد علاقة معنوية بين التزام المنشأة بالمسئولية الاجتماعية

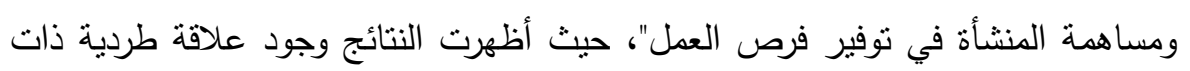

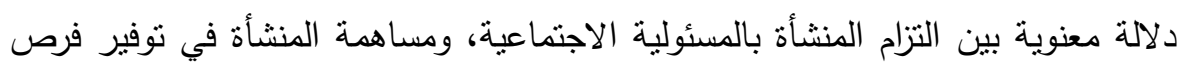
Y2 =3.102+0.325*X+ع

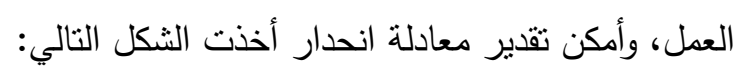
حيث:Y2 مساهمة المنشأة في توفير فرص العمل، Xالنزام المنشأة بالمسئولية الاجتماعية، ع الخطأ العشوائي. r-تم رفض الفرض الثالث: "لاتوجد علاقة معنوية بين التزام المنشأة بالمسئولية الاجتماعية

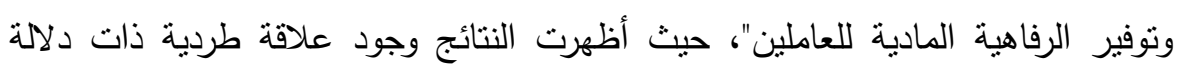
معنوية بين التزام المنشأة بالمسئولية الاجتماعية، وتوفير الرفاهية المادية للعاملين، وأمكن

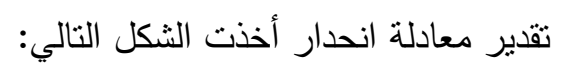
$\mathrm{Y} 3=--1.102+1.343 * \mathrm{X}+\varepsilon$

حيث:Y3توفير الرفاهية المادية للعاملين، التزام المنشأة بالمسئولية الاجتماعية، ع الخطأ

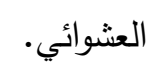
ع-إن إتباع الوحدة الاقتصادية للإفصاح المحاسبي عن المسئولية الاجتماعية في القوائم والتقارير المالية هام لوقف مستخدمي القوائم والتقارير المالية على الآثار الاجتماعية للوحدة الإنية الاقتصادية. 0-الإفصاح المحاسبي عن المسئولية الاجنماعية بمستوى مقبول من الإفصاح يعطي الوحدة

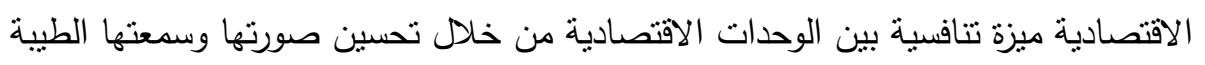

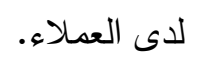


צ-الإفصاح المحاسبي عن المسئولية الاجنماعية يمكن أن يساهم في تحسين الأداء المالي للوحدة الاقتصادية.

\section{اللزوصياهت}

\section{توصي الباحثة بإتباع التالي:}

1-العمل على نطوير النظم المحاسبية القائمة بما يسمح بتوسيع نطاق الإفصاح وذللك من خلال إصدار معيار محاسبي يشنمل على الإفصاح عن المعلومات الاجنماعية والبيئية بجانب المعلومات المالية مما يعمل على تقييم الأداء الثامل للوحدة الاقتصادية.

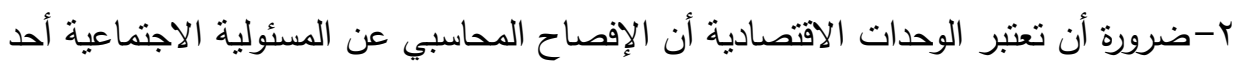

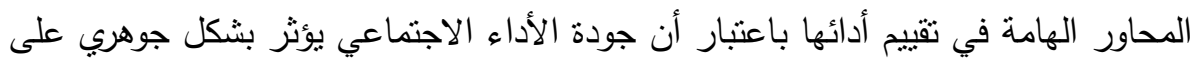
باقي جوانب الأداء المتوازن الأخرى للشركة (المالي - العمليات الداخلية - التحسين

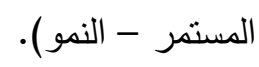

r-العمل على زيادة الوعي لاى المحاسبين في مجال القياس والإفصاح عن الأداء الاجتماعي

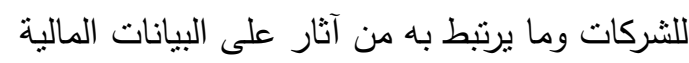
ع-العمل على إدراج الإفصاح عن المسئولية الاجتماعية ضمن خريطة وشجرة حسابات الوحدة الاقتصادية.

ه-العمل على وجود نص قانوني ملزم للإفصاح عن الأداء الاجتماعي للوحدات الاقتصادية.

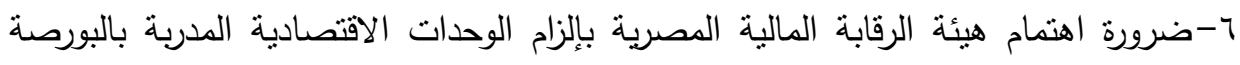

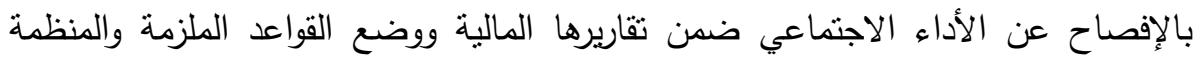




\section{2xyll}

أمين السيد أحمد لطفي(0 . . ب): المراجعة البيئية، (الدار الجامعية)

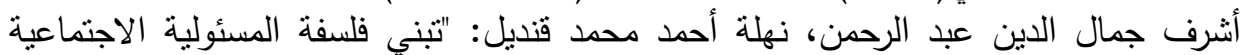

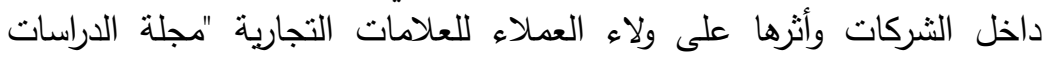

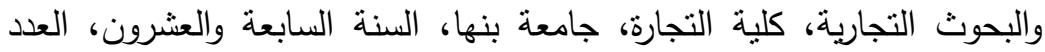

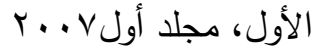

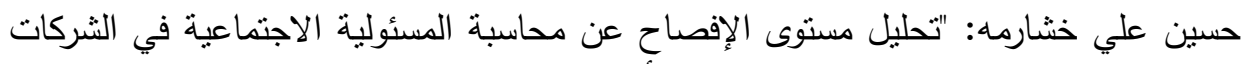

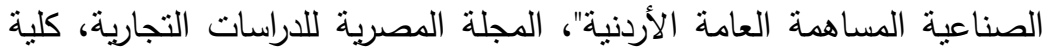

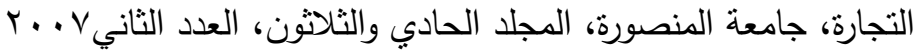

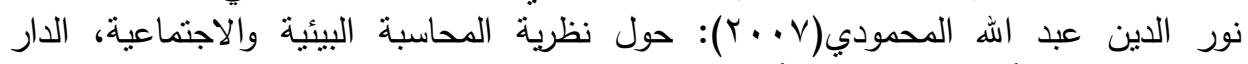
الأكاديمية الطبعة الأولى. (باله.

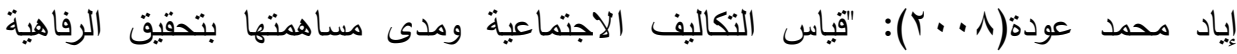
الاجتماعية"، ماجستير المحاسبة مسار الثامل، كلية العلوم المالية والإدارية، الإهاهية جامعة الثرق الأوسط للأدراسات العليا.

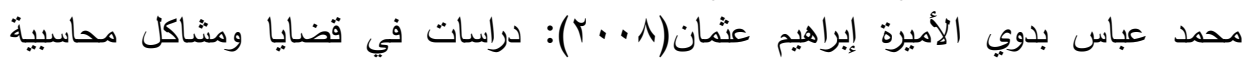
معاصرة المكتب الجامعي الحديث.

نمر عبد الحميد السليحات(9 . . ب): عطا الله القطيش، "دور الحوافز الضريبية لنشركة الاستثمار

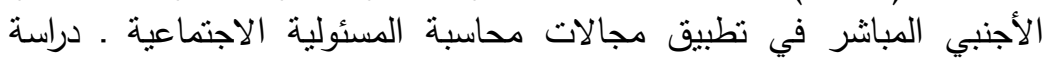
ميدانية على الثركات العاملة في المملكة الأردنية الهاشمية"، مجلة الثانة البحوث

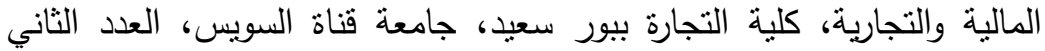

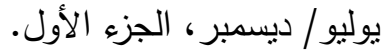

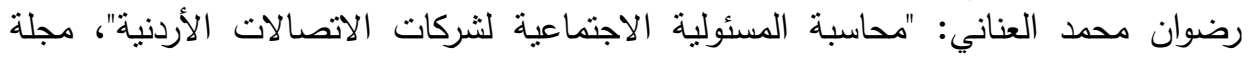

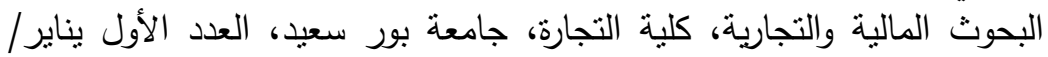

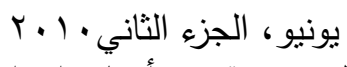

عوض سالم الحربي: "نشرة أخبار الإدارة العربية"، نشرة فصلية تصدر الإنية عن المنظمة العربية

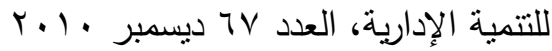

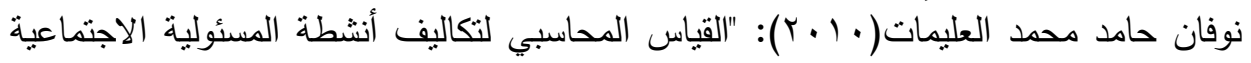

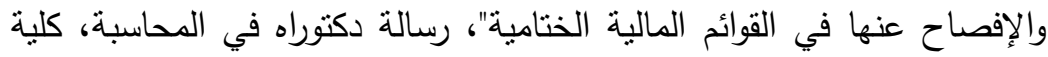




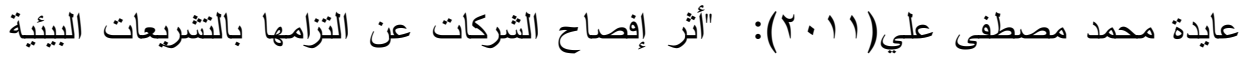

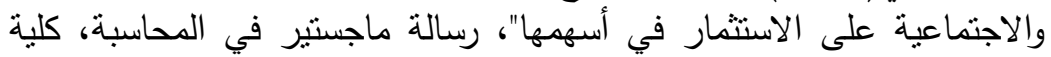
التجارة، جامعة الاسكندرية.

فريد النجار: "المنظومة الجديدة للمسئولية الاجتماعية للشركات"، مجلة الفكر المحاسبي، كلية

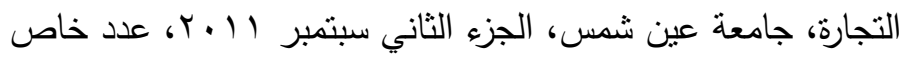

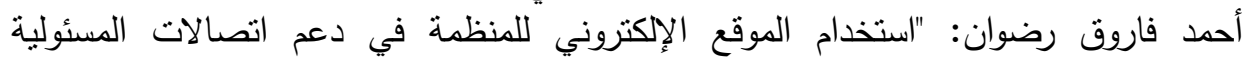

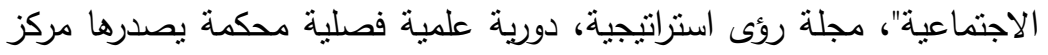

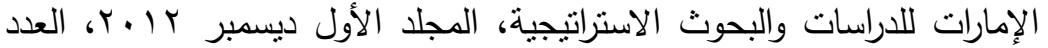

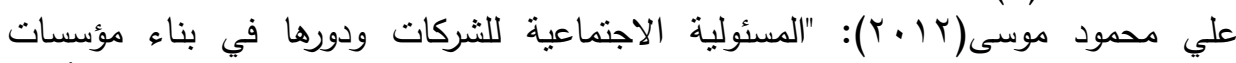

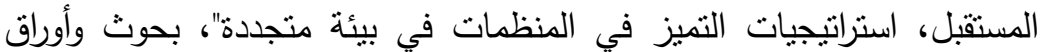

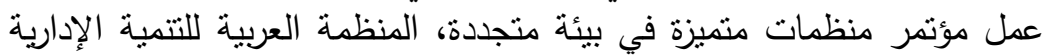

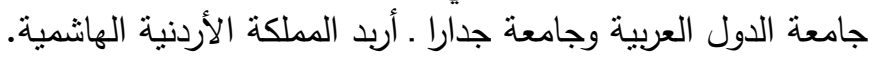

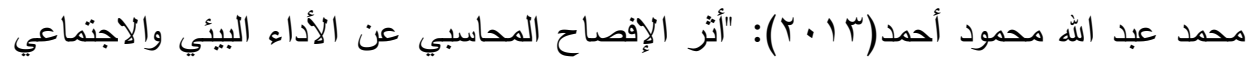

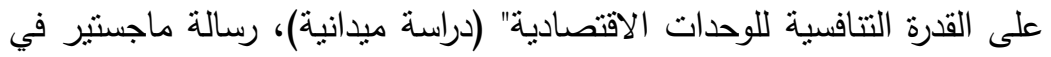

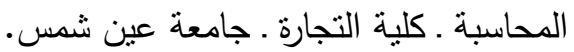

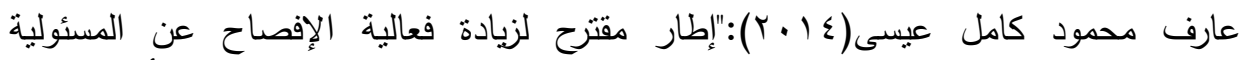

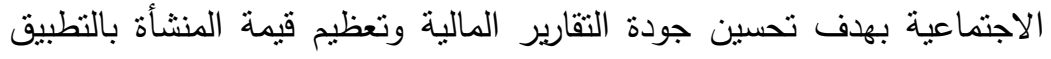

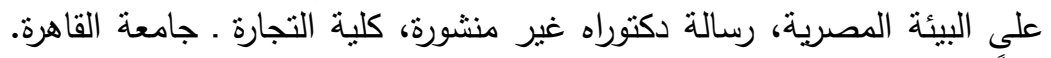

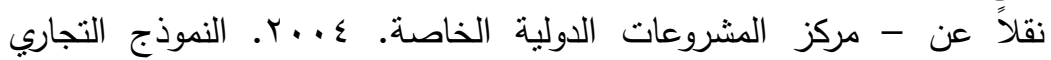

Available at, http://www.cipe-arabia.org. لمواطنة الثركات

علاء الدين توفيق إبراهيم: محددات وحوافز التقرير عن المسئولية الاجنماعية دراسة نطبيقية

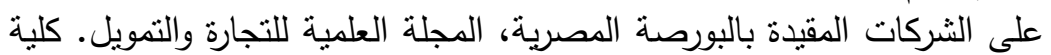

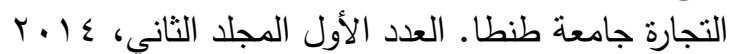

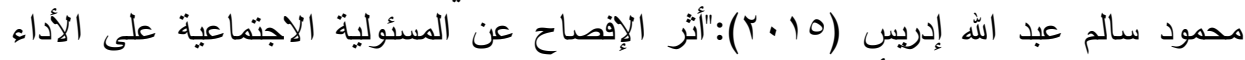

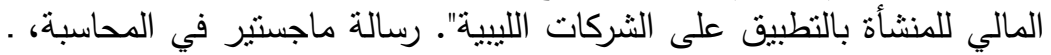

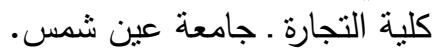

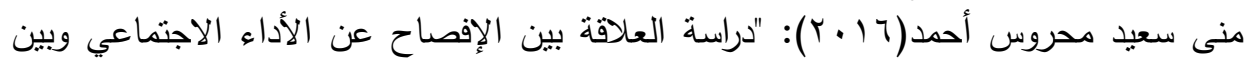

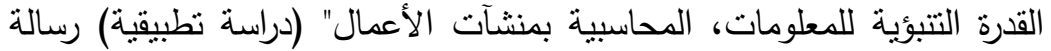

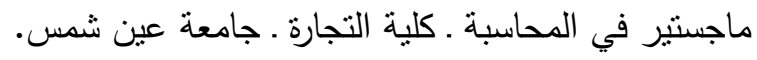

Martin Freedman and A. J. Stagliano, (2004).

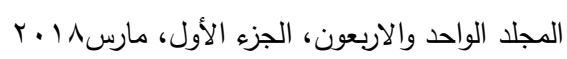




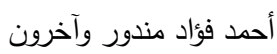

Laurie Ingrid Mook,( 2007) "social and Environmental Accounting: the fxpanded Value Added Statement", Athesis submitted in conformity with the requirements for the degree of Doctor of philosophy Department of Adult Education and Counselling Psychology Ontario Institute for Studies in Education of the University of Toronto.

Isabel sanchez, Jose Aceituno, Luis Rodriguez, (2013)"Determinants of corporate social disclosure in Spanish local governments" , Journal of cleaner Production, Issue39.

\title{
ACCOUNTING DISCLOSURE OF SOCIAL RESPONSIBILITYIN ECONOMIC UNITS
}

Mandour, A. F. ${ }^{(1)}$; Al-Duwairi, S. M. ${ }^{(1)}$ and Saad, Hosnia, H. M. ${ }^{(1)}$ 1) Faculty of Commerce, Ain Shams University

\begin{abstract}
The accounting disclosure of social responsibility in the economic units is one of the accounting functions aimed at expressing the truth about events and transactions with a great deal of objectivity and neutrality to provide the financial and non-financial information necessary to make decisions for the users of the financial statements so as not to be misleading where the financial statements and lists contain all necessary information Which is necessary to show the financial position of the economic unit and to provide that information to those who need it in order to make decisions.

The study aims to study the main objective of studying the effect of accounting disclosure on the role of social performance in economic units and how these units are concerned with the social aspect and fulfilling their social responsibility towards the society in which they work.

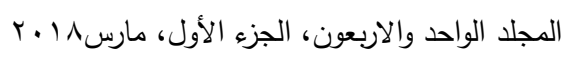


The researcher studied the subject of the study in a theoretical framework for the concept of social responsibility in all its aspects and in a field context by designing a survey questionnaire. The sample included a sample of 150 items distributed equally to the university faculty members to benefit from the academic and scientific experience. (Gulf Oil Company of Suez (GAPCO) - Khaleda Petroleum Company) because this sector is the closest to the subject of the study.

The study concluded with several results, foremost of which was recognition of the importance of social responsibility and its role in making development. The study recommended working on the need to deepen the concept of social responsibility and the commitment of economic units to carry out their social responsibilities towards the society in which they operate. Finance. 